\title{
Quantifying uncertainties from mobile-laboratory-derived emissions of well pads using inverse Gaussian methods
}

\author{
Dana R. Caulton ${ }^{1}$, Qi Li ${ }^{2}$, Elie Bou-Zeid ${ }^{1}$, Jeffrey P. Fitts ${ }^{1}$, Levi M. Golston ${ }^{1}$, Da Pan ${ }^{1}$, Jessica Lu ${ }^{1}$, Haley M. Lane ${ }^{1}$, \\ Bernhard Buchholz $^{3}$, Xuehui Guo ${ }^{1}$, James McSpiritt ${ }^{1}$, Lars Wendt ${ }^{4}$, and Mark A. Zondlo ${ }^{1}$ \\ ${ }^{1}$ Department of Civil and Environmental Engineering, Princeton University, 59 Olden St., Princeton, NJ 08540, USA \\ ${ }^{2}$ Department of Earth and Environmental Engineering, Columbia University, 500 W 120th St., New York, NY 10027, USA \\ ${ }^{3}$ RMS, Technische Universität Darmstadt, Darmstadt, 64287, Germany \\ ${ }^{4}$ Hunterdon Central Regional High School, Flemington, NJ 08822, USA
}

Correspondence: Mark A. Zondlo (mzondlo@ princeton.edu)

Received: 14 October 2017 - Discussion started: 17 November 2017

Revised: 19 July 2018 - Accepted: 4 August 2018 - Published: 22 October 2018

\begin{abstract}
Mobile laboratory measurements provide information on the distribution of $\mathrm{CH}_{4}$ emissions from point sources such as oil and gas wells, but uncertainties are poorly constrained or justified. Sources of uncertainty and bias in ground-based Gaussian-derived emissions estimates from a mobile platform were analyzed in a combined field and modeling study. In a field campaign where 1009 natural gas sites in Pennsylvania were sampled, a hierarchical measurement strategy was implemented with increasing complexity. Of these sites, $\sim 93 \%$ were sampled with an average of 2 transects in $<5$ min (standard sampling), $\sim 5 \%$ were sampled with an average of 10 transects in $<15$ min (replicate sampling) and $\sim 2 \%$ were sampled with an average of 20 transects in 15-60 min. For sites sampled with 20 transects, a tower was simultaneously deployed to measure highfrequency meteorological data (intensive sampling). Five of the intensive sampling sites were modeled using large eddy simulation (LES) to reproduce $\mathrm{CH}_{4}$ concentrations in a turbulent environment. The LES output and LES-derived emission estimates were used to compare with the results of a standard Gaussian approach. The LES and Gaussian-derived emission rates agreed within a factor of 2 in all except one case; the average difference was $25 \%$. A controlled release was also used to investigate sources of bias in either technique. The Gaussian method agreed with the release rate more closely than the LES, underlining the importance of inputs as sources of uncertainty for the LES. The LES was also used as a virtual experiment to determine an optimum number of repeat transects and spacing needed to produce repre-
\end{abstract}

sentative statistics. Approximately 10 repeat transects spaced at least $1 \mathrm{~min}$ apart are required to produce statistics similar to the observed variability over the entire LES simulation period of $30 \mathrm{~min}$. Sources of uncertainty from source location, wind speed, background concentration and atmospheric stability were also analyzed. The largest contribution to the total uncertainty was from atmospheric variability; this is caused by insufficient averaging of turbulent variables in the atmosphere (also known as random errors). Atmospheric variability was quantified by repeat measurements at individual sites under relatively constant conditions. Accurate quantification of atmospheric variability provides a reasonable estimate of the lower bound for emission uncertainty. The uncertainty bounds calculated for this work for sites with $>50 \mathrm{ppb}$ enhancements were $0.05-6.5 q$ (where $q$ is the emission rate) for single-transect sites and $0.5-2.7 q$ for sites with $10+$ transects. More transects allow a mean emission rate to be calculated with better precision. It is recommended that future mobile monitoring schemes quantify atmospheric variability, and attempt to minimize it, under representative conditions to accurately estimate emission uncertainty. These recommendations are general to mobile-laboratory-derived emissions from other sources that can be treated as point sources. 


\section{Introduction}

Reducing emissions of short-lived greenhouse gases through regulations has been considered a potentially viable way to mitigate climate change without intensively regulating $\mathrm{CO}_{2}$, which poses economic and political challenges. In particular, reducing $\mathrm{CH}_{4}$, a potent greenhouse gas and the main component of natural gas, may have significant immediate climate change mitigation benefits (Bowerman et al., 2013; Baker et al., 2015; Zickfeld et al., 2017). However, the large numbers and types of components in the natural gas supply chain that may leak require the development of efficient and accurate methods to quantify emissions. Specifically, techniques that are available to researchers at every level (government, industry and academic) and are accurate enough to locate and quantify specific sources of fugitive emissions and allow for self-monitoring, independent verification and understanding of common leak sources are needed. The range of emissions from these sources can be large as studies have shown that some sources, such as natural gas well pads, have a lognormal distribution where emissions span several orders of magnitude. The most critical targets for mitigation efforts are the super-emitters, where the top $5 \%$ of samples can contribute $\sim 50 \%$ of emissions (Brandt et al., 2016).

To this end, various independent $\mathrm{CH}_{4}$ emission estimation techniques have been implemented. Table 1 shows a brief summary of the methods that have been primarily applied to oil, coal and gas extraction and infrastructure, which account for $\sim 30 \%$ of the total global anthropogenic $\mathrm{CH}_{4}$ emissions (Kirschke et al., 2013). The myriad of sites and types of emission sources have necessitated the development and application of multiple techniques. Examples include satellites (Kort et al., 2014), remote sensing from aircraft (Kuai et al., 2016; Frankenberg et al., 2016; Thorpe et al., 2016), in situ aircraft measurements (Karion et al., 2013, 2015; Peischl et al., 2013, 2015; Caulton et al., 2014; Pétron et al., 2014; Lavoie et al., 2015), long-term monitoring from short and tall towers (Pétron et al., 2012), unmanned aerial vehicles (UAV) (Nathan et al., 2015) and various ground-based techniques. Ground-based techniques include flask sampling (Townsend-Small et al., 2015), tracer correlation techniques (Lamb et al., 2015; Subramanian et al., 2015; Zimmerle et al., 2015; Omara et al., 2016), chamber sampling (Allen et al., 2013, 2014; Kang et al., 2014), thermal and optical imaging (Gålfalk et al., 2016; Ravikumar et al., 2018) and combined measurement-dispersion modeling techniques from stationary (Brantley et al., 2014; Foster-Witting et al., 2015) and mobile platforms (Lan et al., 2015; Rella et al., 2015; Yacovitch et al., 2015).

Every technique has various advantages and disadvantages related to operational cost, sampling efficiency, processing time and uncertainty. These techniques have been used in different ways, from direct point source emission estimation to area source emission rate estimation, and they use data that may span a few hours up to years. For example, Kort et al. (2014) used data spanning over 6 years at $0.33^{\circ}$ resolution covering the entire United States, to estimate a large emission rate. Karion et al. (2013) reported emissions from a large natural gas field $(\sim 60 \mathrm{~km}$ diameter $)$ using aircraft mass balance with data collected within a few hours while Caulton et al. (2014) reported individual well pad emissions $(<1 \mathrm{~km}$ diameter) using the same technique. It is also feasible that as new instruments and data processing techniques become available, any of these techniques may be used at spatial and temporal scales not represented by the works cited here. Table 1 compares the author-reported uncertainties for several techniques; this table is intended to illustrate the motivation for this work and not as an exhaustive review of each of these techniques. These uncertainty estimates should be compared with caution: self-reported uncertainties are not computed in identical manners and some may not include the same sources of uncertainty in their considerations or additional systematic biases to the same extent. Most of the author-reported uncertainties appear to correspond to 1 standard deviation measurements, though the ways in which these statistics are derived are not consistent. Notably, Kort et al. (2014) report a 2 standard deviation range and Pétron et al. (2012) reports a minimum and maximum range for emissions. In addition, several studies report $95 \%$ confidence intervals, such as all ground-based mobile dispersion estimates, likely because of the asymmetric uncertainty that is more easily reported in this manner. The values reported for emission uncertainties, usually significant, are generally not from measurement uncertainties. Even instruments that produce high-accuracy measurements that must be transformed into an emission rate can be confounded by transformation methods that rely upon limited or unrepresentative meteorological conditions such as small-scale turbulence characterization, boundary layer processes or assigning background conditions to a variable atmosphere. Notable, however, is the large range of uncertainties reported by ground-based mobile dispersion techniques. These techniques rely on accurate and precise concentration measurements coupled with dispersion models (Gaussian, AERMOD, WindTrax, etc.) to produce an emission estimate and are subject to various uncertainties in the model, notably atmospheric diffusion coefficients. These techniques are attractive due to their relatively low cost, low computational requirements and high sampling efficiency of individual sources. However, as seen in Table 1, current uncertainty emission estimates using ground-based and mobile measurements seem to underperform relative to other measurement techniques in this field. Therefore, there is a critical need for improved sampling methods and/or data processing in this area to improve data quality and better constrain uncertainty.

\subsection{Theory of the Gaussian plume model}

Approximations of scalar dispersion were investigated as early as the 1930s and were developed to describe non- 
Table 1. Comparison of $\mathrm{CH}_{4}$ emission measurement techniques and reported uncertainties.

\begin{tabular}{llr}
\hline Technique & Referenced study & $\begin{array}{r}\text { Reference } \\
\text { uncertainty range* }\end{array}$ \\
\hline Ground-based thermal imaging & Gålfalk et al. (2016) & $3-15 \%$ \\
Aircraft remote sensing & Kuai et al. (2016), Frankenberg et al. (2016), \\
& Thorpe et al. (2016) & $5-20 \%$ \\
Satellite remote sensing & Kort et al. (2014) & $15 \%$ \\
Chamber sampling & Allen et al. (2013, 2014), Kang et al. (2014) & $20-30 \%$ \\
Ground-based tracer correlation & Lamb et al. (2015), Roscioli et al. (2015), & $20-50 \%$ \\
& Subramanian et al. (2015), Zimmerle et al. (2015), & \\
Aircraft/UAV mass balance & Omara et al. (2016) & $20-75 \%$ \\
& Karion et al. (2013, 2015), Peischl et al. (2013, 2015, & \\
Ground-based stationary dispersion & 2016), Caulton et al. (2014), Pétron et al. (2014), & $25-60 \%$ \\
Tall-tower monitoring & Lavoie et al. (2015), Nathan et al. (2015) & $50-100 \%$ \\
Ground-based mobile dispersion & Pétron et al. (2012) & Lan et al. (2015), Rella et al. (2015), Yacovitch et \\
& al. (2015) & $50-350 \%$ \\
\hline
\end{tabular}

* Uncertainty range reflects author-reported uncertainty on emission numbers, not necessarily measurement uncertainty. Some authors specify a $95 \%$ confidence interval, others use 1 or 2 standard deviations and others compute upper and lower bounds.

reactive pollutant dispersal from elevated stacks (Sutton, 1932; Bosanquet and Pearson, 1936). As models improved, the Gaussian plume model was developed assuming that a scalar concentration has a normal distribution function (Batchelor, 1949; Hilst, 1957). Additional investigation of near-surface conditions where particles can either deposit to or reflect off the surface led to the current Gaussian plume analytical model (shown in Eq. 1) to predict scalar concentrations $(C)$, which can be directly derived from the advectiondiffusion equation under some simplifying assumptions (as explained in Veigele and Head, 1978). Variations of this equation can be found in many papers and textbooks (for example Gifford Jr., 1968; Zannetti, 1990). The Gaussian model with a reflective ground $\left(\mathrm{CH}_{4}\right.$ is reflected off the surface) is presented here:

$C(x, y, z)=\frac{Q}{2 \pi \sigma_{y} \sigma_{z} u} \cdot e^{\frac{-y^{2}}{2 \sigma_{y}^{2}}} \cdot\left[e^{\frac{-(z-h)^{2}}{2 \sigma_{z}^{2}}}+e^{\frac{-(z+h)^{2}}{2 \sigma_{z}^{2}}}\right]$.

This function relies on the 3-D distances $(x, y, z)$ of a receptor from a source as well as the source height $h$; mean horizontal wind speed $u$; and a source strength, $Q$. Here, the source is defined as the origin with $x$ the downwind distance, $y$ the crosswind distance and $z$ the measurement height above ground. The dispersion coefficients $\left(\sigma_{y}, \sigma_{z}\right)$ encode the strength of turbulent mixing or diffusivity, as well as the downwind distance over which the mixing is performed, $x$, which does not appear directly in Eq. (1). They are calculated according to any of several analytical parameterizations based on Pasquill-Gifford's stability class scheme. Atmospheric stability classes range from very unstable $(A)$ to very stable $(F)$. Class D is defined as neutral. The model describes the distribution of a scalar concentration $(C)$ downwind of a source, meaning it describes average plume locations and concentrations. However, the instantaneous observed plume structure deviates greatly from the average behavior, with fluctuating peak concentration magnitude and location. The comparison of instantaneous and modeled concentrations is thus impacted by the averaging timescale associated with the measurements. Studies suggest that appropriate timescales depend on downwind distance, $x$, and stability ranging from 2 to $60 \mathrm{~min}$ (Fritz et al., 2005). For example, in class D at $200 \mathrm{~m}$ downwind, $3 \mathrm{~min}$ would be sufficient when using the Gifford dispersion coefficients. Insufficient averaging would result in random errors that we refer to in this work as the uncertainty related to atmospheric variability.

The Gaussian plume model is used to calculate emissions by comparing the model output to the observations. This can be done in a variety of ways. The stationary dispersion techniques used by Brantley et al. (2014) and FosterWittig et al. (2015) utilize the model at a single point and relate changes in concentration to changes in wind direction and thus speed. These procedures either follow, or are related to, the well-defined U.S. Environmental Protection Agency (EPA) OTM 33A and are not discussed further (U.S. EPA, 2014). The mobile dispersion techniques investigated in this study and others (Lan et al., 2015; Rella et al., 2015; Yacovitch et al., 2015) compare observed concentrations at continuous downwind $x$ and $y$ locations (i.e., along a road) to the modeled output along this road. Various techniques have also incorporated averaging schemes and additional $z$ dimensional data (Lan et al., 2015; Rella et al., 2015). Wind direction and speed are either fixed to the prevailing direction or rotated to match the observations. While data can be collected and processed quickly, the application of a Gaussian model that describes average plume behavior to instan- 
taneous data has apparent shortcomings and no standard uncertainty protocol has been established.

\subsection{Previous work}

Robust uncertainty analyses of Gaussian emission retrievals are not reported in most studies, which instead focus on the novel application of the methods. Yacovitch et al. (2015) reported an asymmetric $95 \%$ confidence interval on their emission rates of $0.334-3.34 q$, where $q$ is the reported emission rate by using a controlled release as a proxy. Lan et al. (2015) used a Monte Carlo approach based on assumed uncertainty in source height, wind speed and wind direction for an average $95 \%$ confidence interval of roughly $0.5-1.5 q$. Rella et al. (2015) also used a controlled release to calculate the variation in their measurement of a constant emission and reported a $95 \%$ confidence interval of $0.28-3.6 q$. These methods report uncertainty analyses that apply to a single site (i.e., one well pad regardless of how many times it was actually sampled), though it should be noted that Rella et al. (2015) and Yacovitch et al. (2015) used downwind transects while Lan used stationary time-averaged measurements. Notably, Lan et al.'s (2015) Monte Carlo method produced the smallest confidence interval, but accounted only for assumed uncertainty in three parameters and may neglect other factors (distance, stability, emission variability). The controlled release method employed by Yacovitch et al. (2015) and Rella et al. (2015) is useful in that direct observations of measurement variability can be made and potential bias in the measurements can be determined. However, these methods produce large uncertainty ranges and it is unclear if they can reliably separate large emissions (e.g., emissions $>10 \times$ the mean) from mean emissions. Additionally, implementing a controlled release is not trivial due to long setup times of equipment and restricted access to locations suitable for the release. These conditions may make a controlled release experiment prohibitive for many applications with strict time or budget constraints or for those where site access is limited. As a goal of this work is to identify best practices for quantifying uncertainty, it is important to understand how feasible a given method is likely to be.

The Gaussian model is attractive as a method for inferring emission rates as it is fast and generalizable with the ability to account for changes in stability, wind speed and source elevation. However, the uncertainties for this method change depending upon how it is implemented and whether it is extended to situations outside the reasonable limits of the generalized form. Such situations would include using the average Gaussian plume model with instantaneous measurements without uncertainty or sensitivity analysis or applications over complex topography. A method for implementation of this technique that identifies best practices and is supported by observations and modeling is needed.

In our study, we combine traditional Gaussian methods, advanced large eddy simulation (LES) modeling and a con- trolled release to assess in situ variability of emission retrievals from $\mathrm{CH}_{4}$ plumes downwind of natural gas well pads in the Marcellus Shale in Pennsylvania. We also investigate sources of potential bias in the controlled release and modeling methods. The basic architecture of our approach to quantify errors associated with mobile Gaussian methods uses (1) advanced modeling of a preselected sample site to enable investigation of optimum sampling strategies, (2) application of strategies to the sample collection process and (3) evaluation of additional sources of uncertainty and bias using advanced modeling and a controlled release.

\section{Methods}

\subsection{Instrumentation}

Field data were collected in Pennsylvania during three campaigns in July 2015, November 2015 and June 2016 using the Princeton atmospheric chemistry experiment (PACE). PACE is a Honda CR-V that has been modified to accommodate a roof rack that holds sensors $\sim 1 \mathrm{~m}$ above the car to limit the possibility of self-sampling. The roof rack is equipped with a LI-COR 7700 to measure $\mathrm{CH}_{4}$ and LI-COR $7500 \mathrm{~A}$ to measure $\mathrm{CO}_{2}$ and $\mathrm{H}_{2} \mathrm{O}$; both sensors record at $10 \mathrm{~Hz}$. Meteorological data and GPS data were collected at $1 \mathrm{~Hz}$ with a Vaisala WXT520 and Garmin unit in July 2015 and June 2016 and with an Airmar WS-200WX in November 2015. More information on the mobile lab design and instrumentation can be found in Tao et al. (2015). The LICOR sensors were calibrated prior to each campaign using a blank $\left(\mathrm{N}_{2}\right)$ and a $2.12 \mathrm{ppm} \mathrm{CH}_{4}$ standard in air and were also periodically calibrated with a $1.8724 \pm 0.0030 \mathrm{ppm} \mathrm{CH}_{4}$ and $394.51 \pm 0.07 \mathrm{ppm} \mathrm{CO}_{2}$ NOAA standard. The high stated measurement range of the LI-COR 7700 (40 ppm) and the excellent stability of the instrument allow for calibration with a relatively low concentration standard (McDermitt et al., 2010). In addition, enhancements observed were usually less than a few ppm above the ambient concentration. Data were synchronized and logged using a custom LabVIEW program.

In addition, at select sites, a tower was set up to measure high-frequency meteorological data. This tower included a second pair of LI-COR 7500A and 7700 along with a METEK uSonic-3 Class A sonic anemometer to measure the three-dimensional instantaneous wind vector. The tower was typically set alongside the road at a height between 2 and $3 \mathrm{~m}$. Initially, the tower was constructed using a standard tripod, but was later adapted to the bed of a pickup truck to allow faster deployment. The air flow around the pickup truck was modeled (using Fluent, http://www.ansys.com/Products/ Fluids/ANSYS-Fluent, last access: 1 May 2018.) to determine the optimum placement of sensors above the vehicle to minimize local flow distortions. Three orientations were tested, with the truck cab facing 0,90 and $180^{\circ}$ with a $0^{\circ}$ mean wind flow. Deflection was observed in all three cases, 


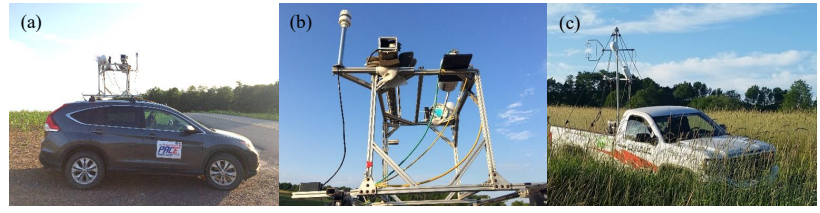

Figure 1. (a) The Princeton atmospheric chemistry experiment (PACE), (b) close-up of the PACE roof rack with instrumentation and (c) the mobile tower platform.

but the distortion was minimal at $\sim 2 \mathrm{~m}$ above the pickup bed. The final design of the mobile lab, the instrumentation rack and the mobile tower are shown in Fig. 1.

\subsection{Hierarchical sampling}

Unconventional natural gas well pads were selected for sampling using a pseudo-random method to efficiently isolate sites that could be measured from public roads with the prevailing wind direction. All datasets were accessed from the Pennsylvania Spatial Data Access (www.pasda.psu.edu, last access: 1 May 2018). Sites were screened to remove those that were far ( $>300 \mathrm{~m}$ from public road), had obstructions (buildings and full tree lines) or had large elevation differences between the well and the roadway $(>50 \mathrm{~m})$. These characteristics were determined to be the most crucial for successfully sampling sites in this area as topography and vegetation made detecting plumes farther than $300 \mathrm{~m}$ difficult as the source could not be visually verified. The direction from the nearest public road was used to separate sites that could be measured with four prevailing wind conditions $(\mathrm{N}, \mathrm{E}, \mathrm{W}, \mathrm{S})$. This resulted in a database of screened sites for each wind direction that could be used to make measurement routes. Routes were primarily planned for efficiency around the forecast mean wind direction; however, the distribution of the sample relative to the population of key factors (well age, production and operator) was routinely examined to identify and correct for over and underrepresentation. These data were collected at different hierarchical levels based on the length of time collection took, complexity of data collected and analysis method. The data collected at each level are summarized in Table 2. A discussion of the details and rationale of the sampling strategy can be found in Sect. 3 .

As a source of validation, an experimental controlled release of $\mathrm{CH}_{4}$ was also performed. The controlled release allows the retrieved emissions to be compared to known emission rates from a constant source. A pure $(99.5 \%) \mathrm{CH}_{4}$ cylinder was vented at various controlled flow rates to produce different measurable emission rates. The release site was selected for flat, open topography and isolated from any potential sources. Background transects were collected for approximately 30 min before releasing $\mathrm{CH}_{4}$ to ensure no contaminating signals would be detected. An interfering $\mathrm{CH}_{4}$ signal from a large mulch pit was detected and the release setup was moved away from the source to ensure no signal mixing. The cylinder was set $\sim 100 \mathrm{~m}$ from a public road at an altitude of $1 \mathrm{~m}$. The release was performed over several hours, during the afternoon and evening to span different stability classes. Figure S1 in the Supplement shows a diagram of the release setup.

\subsection{Inverse Gaussian method (IGM)}

The IGM approach has been used extensively as described in Sect. 1.1. Applied here, the method uses the sampled source location as input to first identify downwind transects. The peak $\mathrm{CH}_{4}$ location and the known source location are used to define the prevailing wind direction and centerline plume ( $x$ in Eq. 1). The along-wind and crosswind ( $y$ in Eq. 1) distances are then calculated using the synchronous GPS data. Distances are calculated for each measurement point as a transect may not necessarily be perpendicular to the wind. The receptor altitude ( $z$ in Eq. 1) is fixed at $2.5 \mathrm{~m}$, the height of the instrumentation above the road. Unless measured at intensive sites with a tower, wind speed and stability are taken from NOAA's Ready archived meteorology (https://www.ready.noaa.gov, last access: 1 May 2018, Rolph et al., 2017) because mobile wind data showed artefacts after corrections for vehicle heading. These artefacts included unreasonably high wind speed and little correlation to stationary tower measurements. The NOAA Ready archive meteorology dataset is from the National Center for Environmental Prediction's Eta Data Assimilation System model (EDAS, information at https://ready.arl.noaa.gov/edas40.php, last access: 1 May 2018, Black, 1994). These climate analysis data are available in $3 \mathrm{~h}$ increments at $40 \mathrm{~km}$ resolution and constant pressure coordinates. The data were interpolated to $1 \mathrm{~h}$ resolution for use in the model. The hourly data are matched to the closest observation based on time. The stability data are used to identify the proper $z$ and $y$ dispersion parameters based on Briggs (1973) for rural areas in the downwind regime between 100 and $10000 \mathrm{~m}$. While there is uncertainty in using interpolated model wind speed and stability, especially as conditions can change in the morning and evening, the sampling period per site lasted on timescales of a few minutes. At this temporal scale, wind speed, stability and turbulence statistics are assumed to be constant. During rapidly changing conditions, the model-interpolated wind speed and stability could indeed be incorrect. The effects of uncertainties in wind speed and stability are discussed in Sect. 5.1.

As discussed in Sect. 1.1, the comparison between the observations and modeled output along a downwind transect is used to calculate emission rate. First, the local background ( $C_{\text {Background }}$ ), defined as the $\mathrm{CH}_{4}$ minimum over the transect, is subtracted from observations of a plume ( $\left.C_{\text {observation }}\right)$ to produce an enhancement value. The uncertainty of the background selection in the specific context of this work is discussed in Sect. 5.1. Second, Eq. (1) is solved for the $x$ and $y$ measurement points of the measured transect using 
Table 2. Summary of acquired data and data level.

\begin{tabular}{lrrrllr}
\hline Sample type & $\begin{array}{r}\text { No. of } \\
\text { samples }\end{array}$ & $\begin{array}{r}\text { Average No. } \\
\text { of transects }\end{array}$ & $\begin{array}{r}\text { Measurement } \\
\text { time (min) }\end{array}$ & $\begin{array}{l}\text { Wind } \\
\text { source }\end{array}$ & $\begin{array}{l}\text { Emission } \\
\text { calculation } \\
\text { technique }\end{array}$ & Level \\
\hline Standard sample & 940 & 2 & $1-5$ & NOAA & IGM & 1 \\
Replicate sample & 53 & 10 & $5-15$ & NOAA, on-site & IGM & 2 \\
Intensive sample & 17 & 20 & $15-60+$ & On-site & IGM, LES & 3 \\
\hline
\end{tabular}
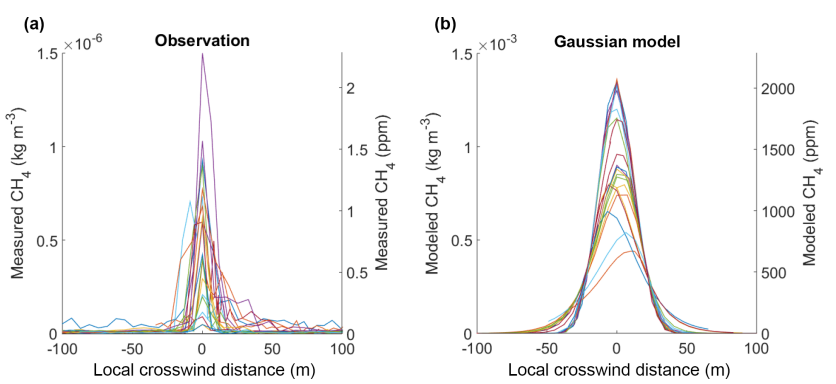

Figure 2. (a) Observations of $\mathrm{CH}_{4}$ at a site showing multiple downwind transects versus the local crosswind ( $y$ ) distance. (b) Gaussian plume model outputs along the same downwind transects. Note that the scale difference between the panels is due to the inverse methodology used where the model is set to a reference emission rate (of $1 \mathrm{~kg} \mathrm{~s}^{-1}$ ).

a reference model emission rate $\left(Q_{\text {ref }}\right)$ taken arbitrarily to be $1 \mathrm{~kg} \mathrm{~s}^{-1}$ to produce $C_{\text {model }}$. The ratio between the observations and model is used to infer the observed emission rate. Again, the peak observation value is used to define the plume centerline for the Gaussian model for each transect. A comparison of observations and model output from 21 downwind transects is shown in Fig. 2. Note that the roads were not necessarily perpendicular to the wind; therefore, the superposition of the plume on the roadway may not show a full Gaussian profile. Third, the observations and modeled concentrations are both integrated along $y$ (summed since they consist of discrete points) as previously recommended by Albertson et al. (2016) to minimize the influence of the random variability of the instantaneous plume. Finally, because the concentrations scale linearly with the emission rate according to Eq. (1), the emission rate can be estimated as shown in Eq. (2):

$Q=\frac{\sum C_{\text {Observation }}-C_{\text {Background }}}{\sum C_{\text {Model }}} \times Q_{\text {ref }}$,

where $\Sigma$ implies summation over $y$. This method of integrated concentrations has the advantage of not relying on regressions between the instantaneous data and model data which may have very low correlation as the instantaneous plume is not expected to adhere to a Gaussian profile on such a short timescale, even when a few transects are averaged. It should also be noted that under ideal conditions (e.g., road perpendicular to prevailing wind direction), integrating the Gaussian equation (Eq. 1) in $y$ creates a Gaussian profile independent of the choice of horizontal diffusion $\left(\sigma_{y}\right)$. As the vertical diffusion $\left(\sigma_{z}\right)$ is expected to be independent of averaging time (CCPS, 1996), this also has the advantage of minimizing the effect of different measurement timescales when comparing the observations to the Gaussian model, which are described in Fritz et al. (2005).

\subsection{Large eddy simulation}

Large eddy simulation (LES) is used to simulate the dispersion of $\mathrm{CH}_{4}$ for sites that had been sampled with a tower for approximately $1 \mathrm{~h}$ and sampled with the mobile lab with at least 10 transects at both the beginning and end of the observation period. The LES turbulent modeling technique is the most suitable for high-Reynolds number flow and dispersion in the atmospheric boundary layer. The LES code used in this study has been widely validated (Bou-Zeid et al., 2005; Tseng et al., 2006; Li et al., 2016b). Briefly, the LES code solves the resolved continuity, Navier-Stokes, and scalar conservation equations on a Cartesian grid and models the unresolved motions using the Lagrangian scaledependent dynamic subgrid-scale model (Bou-Zeid et al., 2005). The sharp interface (Mittal and Iaccarino, 2005) immersed boundary method is used to simulate flow with the presence of large solid structures (e.g., tanks in this study) in the field (Chester et al., 2007; Li et al., 2016b; Tseng et al., 2006). Scalar sources are located on top of the structures or at other points around the source structure if needed to simulate the gas emissions. A more detailed description of how sources were selected is presented in Sect. 4.1.

A pseudo-spectral method is used for horizontal spatial derivatives and a second-order finite difference method is used for a vertical spatial derivative with the needed treatments to overcome the Gibbs phenomenon following Li et al. (2016a). The second-order Adams-Bashforth method is used for time integration. The inflow velocity is a turbulent logarithmic profile generated from a separate simulation over homogeneous flat terrain mimicking upwind conditions. The inflow scalar is kept at a constant background concentration.

In total, five sites were simulated in neutral conditions. Most sites were set up with 1 or $2 \mathrm{~m}$ horizontal and vertical grid resolution with a total simulation domain size of $256 \mathrm{~m}$ in $x$ (along-wind) and $y$ (crosswind) directions and $100 \mathrm{~m}$ in 
$z$ (vertical) direction. Site 5, the controlled release, was set up with $1 \mathrm{~m}$ horizontal resolution and $0.2222 \mathrm{~m}$ vertical resolution with a full $z$ dimension of $33.33 \mathrm{~m}$. This was done because the release source is at a low elevation and such high resolutions are needed by LES to resolve a sufficient fraction of the turbulent scales near the surface. It is important to note that all sites were set up to ensure that the vertical dimension was at least $10 \times$ the tallest simulated obstruction, which is equal to the height of the emission sources. This is significant as, according to Townsend's theory of attached eddies, turbulent scales that contribute significantly to the vertical diffusion of a plume are proportional to the distance of this plume from the surface (thus attached to the surface, Townsend, 1961). Townsend's theory has been confirmed experimentally by many studies (Perry and Li, 1990; Nickels et al., 2007; Woodcock and Marusic, 2015) for near-neutral conditions. Since the domain size of the LES will limit itself to the largest scale of eddies that can be resolved, the large $z$ dimension used for these sites will allow full contributions from eddies of the same size up to 1 order of magnitude larger than the emission point elevation, which will diffuse and spread the plume. The real atmospheric boundary layer might contain even larger eddies (up to $\sim 1 \mathrm{~km}$ ) that are not captured in the LES; since these eddies are much larger than the source height and thus the plume cross-sectional scale, they will cause plume meandering, but will not diffuse the plume in the $y$ and $z$ directions. As a result, LES might underestimate plume meandering, a point that will be revisited in Sect. 4.2.

Site layouts are shown in Fig. 3. Sites were simulated for at least $30 \mathrm{~min}$ to allow the simulated turbulence to reach a statistically stationary state, where the average and standard deviations of the wind and scalars approach a constant value as shown in Fig. S2. The equations solved in LES are non-dimensionalized using the friction velocity $\left(u_{*}\right)$. The advantage is that results from LES apply more broadly to any problem when the non-dimensional quantities, e.g., as $u_{\text {nondimensional }}=u / u_{*}$, are considered. LES outputs can then be scaled (dimensionalized) with the measured field friction velocity and the scalar flux rate imposed in the simulation to match the reference emission of $Q_{\text {ref }}=1 \mathrm{~kg} \mathrm{~s}^{-1}$ that allows direct comparison to the Gaussian model estimates. Table 3 summarizes conditions and domain parameters for all five sites. Sites were primarily selected for simple geometry with flat terrain and homogeneous upwind conditions. Generally, elevation differences across the domains were less than $4 \mathrm{~m}$ and structures could be easily seen and photographed from the road to aid in site setup.

\section{Sampling strategy}

\subsection{Model-based design of sampling strategy}

LES has been previously used to investigate plume dispersion and is used here as a reference that represents the best estimate for the "truth" of how a plume evolves in a turbulent near-neutral environment (Nieuwstadt and de Valk, 1987; Weil, 1990; Wyngaard and Weil, 1991; Mason, 1992; Weil et al., 2004). A useful extension of the LES analysis would be to examine the output as a reference case to understand how sampling the model environment by taking instantaneous measurements of the concentration fields affects emission retrievals. The turbulent structures that LES can resolve are illustrated in Fig. 4, which contrasts instantaneous plumes and averaged plumes in both the horizontal streamwise $(x-y)$ and vertical crosswind $(y-z)$ perspective. To optimize sampling there are two important variables: (1) the number of measurements and (2) the time interval between measurements. Increasing the number of measurements is expected to increase the accuracy of the retrieval; however, the time interval may also affect results as measurements with short spacing may resample the same coherent plume and thus the same plume realization (Metzger at al., 2007; Shah and Bou-Zeid, 2014).

Using the LES output, which is saved with $1 \mathrm{~Hz}$ resolution to match our instrument sampling frequency, sample transects were picked from the full time series, varying the number of repeat transects and their time intervals. Time intervals of $30 \mathrm{~s}, 1 \mathrm{~min}, 2 \mathrm{~min}$ and random (meaning the time interval was not consistent or constrained) were imposed upon the sample picks and the number of repeat transects ranged from 1 to 70 . These transects were then integrated and used as $C_{\text {observation }}$ in Eq. (2) (LES is the experiment here) and the average LES profile was used as $C_{\text {Model }}$ to produce an emission rate. For each combination of transect number and time spacing, 100 random samples were picked and the mean and standard deviation of the emission rate were calculated and compared to the known LES emission rate. An ideal scenario would result in a low percent difference (pd) and a standard deviation of the sample that is roughly equal to the standard deviation of a fully random sample (random time spacing). The random time spacing should be representative of a fully random sample as points are drawn from the full $30 \mathrm{~min}$ time simulation and are less likely to resample similar plume structures. Standard deviations are being compared instead of standard error as each sample strategy is being treated as a population so that the resulting standard deviation may be used as an approximation of the population standard deviation. The results for the 100 random samples are shown in Fig. 5, highlighting the 5th to 95th percentile span of the results for different numbers of transects. The effect of increasing the number of measurements clearly reduces the range of retrievals, but the benefits of adding transects becomes incremental around 10 samples beyond which increasing the 

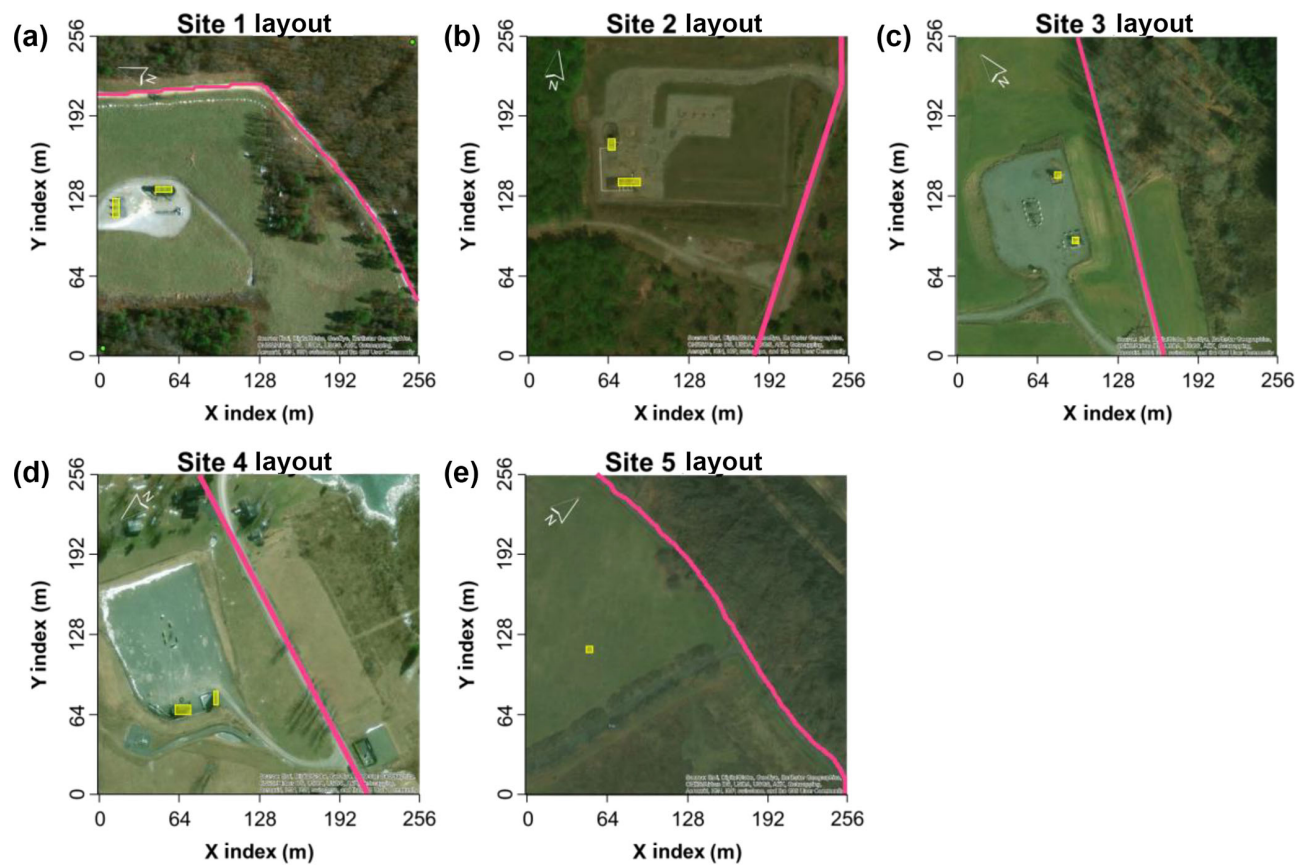

Figure 3. Site layouts showing emitting structures in yellow and the road in magenta for (a) Site 1, (b) Site 2, (c) Site 3, (d) Site 4 and (e) Site 5. Wind is always entering the domain from the left.

Table 3. Summary of LES site conditions and parameters.

\begin{tabular}{lrrrrr}
\hline Characteristic & Site 1 & Site 2 & Site 3 & Site 4 & Site 5* \\
\hline Sample date & 15 Jul 2015 & 21 Jul 2015 & 21 Jun 2016 & 23 Jun 2016 & 5 Aug 2016 \\
Time (EDT) & $18: 15-20: 15$ & $07: 00-09: 15$ & $09: 45-10: 30$ & $20: 00-20: 30$ & $16: 15-20: 00$ \\
No. of transects & 26 & 28 & 21 & 22 & 81 \\
Wind speed $\left(\mathrm{m} \mathrm{s}^{-1}\right)( \pm 1 \sigma)$ & $1.30 \pm 0.64$ & $1.30 \pm 0.70$ & $1.9 \pm 2.2$ & $0.62 \pm 0.27$ & $1.70 \pm 0.89$ \\
Wind direction $( \pm 1 \sigma)$ & $325 \pm 101$ & $252 \pm 40$ & $276 \pm 50$ & $40 \pm 47$ & $218 \pm 28$ \\
Friction velocity $\left(\mathrm{m} \mathrm{s}^{-1}\right)$ & 0.26 & 0.29 & 0.48 & 0.18 & $0.10-0.21$ \\
Distance from source $(\mathrm{m})$ & 176 & 154 & 29 & 49 & 110 \\
Number of sources & 2 & 2 & 2 & 2 & 1 \\
Height of sources $(\mathrm{m})$ & 5,8 & 5,8 & 5,8 & 5,8 & 1 \\
Elevation gain $(\mathrm{m})$ & 3.5 & 1.5 & 2 & 2 & 2 \\
Simulation stability & $\mathrm{D}$ & $\mathrm{D}$ & $\mathrm{D}$ & $\mathrm{D}$ & $\mathrm{D}$ \\
Simulation time $(\mathrm{min})$ & 59.2 & 33.33 & 33.33 & 33.33 & 30 \\
Simulation warm-up time $(m i n)$ & 10 & 5 & 5 & 5 & 5 \\
Simulation $x$ dimension $(\mathrm{m})(x$ resolution$)$ & $288(2)$ & $256(1)$ & $256(1)$ & $256(1)$ & $256(1)$ \\
Simulation $y$ dimension $(\mathrm{m})(y$ resolution $)$ & $256(2)$ & $256(1)$ & $256(1)$ & $256(1)$ & $256(1)$ \\
Simulation $z$ dimension $(\mathrm{m})(z$ resolution$)$ & $100(1)$ & $100(1)$ & $100(1)$ & $100(1)$ & $33.33(0.2222)$ \\
\hline
\end{tabular}

* Controlled release site.

number of transects reduces the retrieval scatter very slowly (individual box plots are available in Fig. S4). The 5-95\% range of observations for absolute percent difference (always relative to the mean of the compared observations) decreases by $60 \%$ at 10 transects, but only decreases by an additional $10 \%$ by extending up to 70 transects. The $5-95 \%$ range of observations for relative standard deviation (rsd) follows a similar but less extreme pattern with the range of observa- tions decreasing by $20 \%$ up to 10 transects and decreasing by an additional $15 \%$ by extending up to 70 transects. Additionally, retrievals with $30 \mathrm{~s}$ spacing show increased bias (seen by higher absolute pd) as even high numbers of samples may measure plume structures that are similar as indicated by the low scatter, but are not very representative of the whole simulation. However, the $1 \mathrm{~min}, 2 \mathrm{~min}$ and random intervals look very similar, indicating a 1 min interval can 
(a) Site 3 instantaneous scalar $(Z=3 \mathrm{~m})$

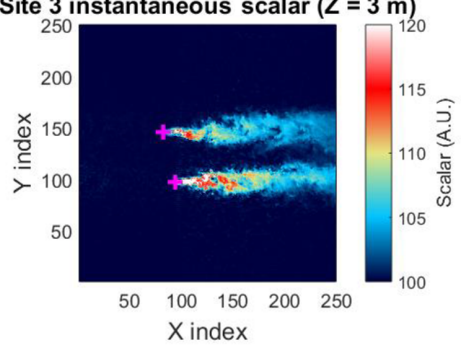

(c) Site 3 instantaneous scalar $(X=225 \mathrm{~m})$

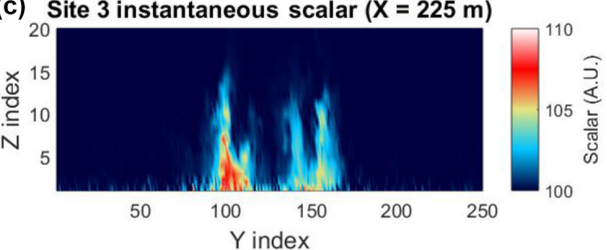

(b) Site 315 minute average scalar $(Z=3 \mathrm{~m})$

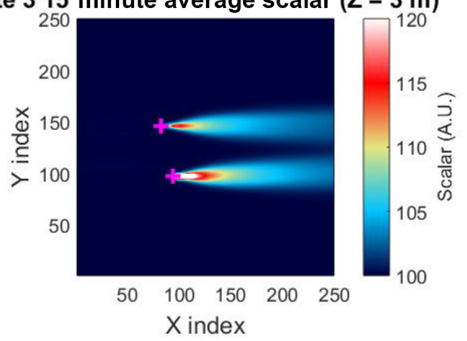

(d) Site 315 minute average scalar $(X=225 \mathrm{~m})$

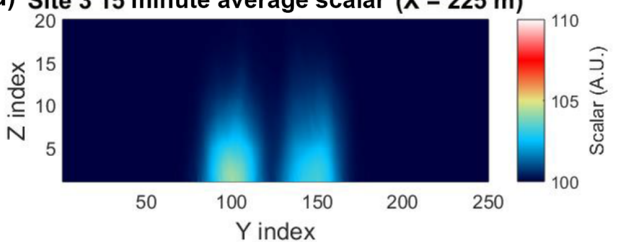

Figure 4. Comparison of instantaneous (a, c) and 15 min averaged (b, d) plume for Site 3 from the LES. Panels (a) and (b) show the scalar with arbitrary units (A.U.) in (a) $x-y$ cross section at an altitude of $3 \mathrm{~m}$ and panels (c) and (d) show a $x-z$ cross section at a $225 \mathrm{~m}$ downwind distance. The release locations are shown with a magenta marker (+).
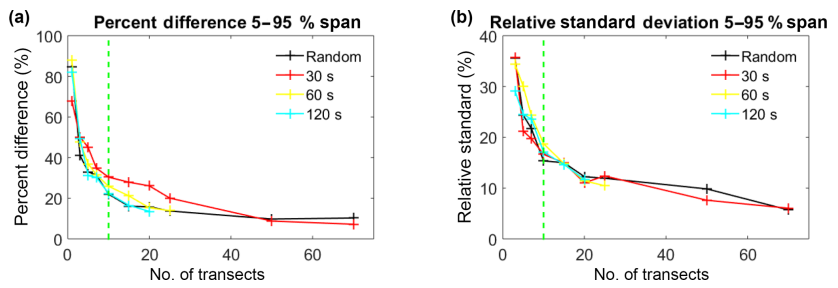

Figure 5. The 5-95\% percent difference (a) between emission retrieval and known simulation emission rate and (b) between relative standard deviation (rsd) of the emission retrieval using various amounts of transects and random, $30 \mathrm{~s}, 1 \mathrm{~min}$ or $2 \mathrm{~min}$ transect spacing. The recommended 10-transect criteria are shown in green.

be used as a practical lower limit (this might somewhat depend on turbulence intensity and stability in the atmosphere, however). Notably, the random time spacing sample shows an rsd of $\sim 25 \%$ even at the maximum number of repeat measurements (70). This confirms that there is variation in the quantified emission rate expected simply due to atmospheric variability. Atmospheric variability may have many sources; in these simulations, variability is only attributable to turbulence. However, in a real dynamic environment atmospheric variability could also include effects of mean wind flow change and plume meandering, especially in low wind speed conditions (Vickers et al., 2008; Mortarini et al., 2016). Another way of describing the atmospheric variability as used in this work would be transect to transect variability, which encompasses all random errors that lead to differences between one transect through the plume and the next. These are hence the errors associated with insufficient averaging of the turbulent field and would be reduced as the number of averaged transects increases (Salesky and Chamecki, 2012).
These results indicate that, in order to sample such that the measurements minimize the effect of these random errors, sites must be sampled with at least 10 transects with $>1 \mathrm{~min}$ spacing.

\subsection{Field implementation}

Field measurements were designed to target neutral stability found in the morning and evening with each sampling outing typically lasting $4 \mathrm{~h}$; this minimizes the errors related to assigning stability and coincides with LES conditions. Most sites were sampled 1-3 times (denoted as standard sampling), occasional sites were sampled with $\sim 10$ transects (replicate sampling) and a few sites were sampled with $>10$ transects as well as a tower (intensive sampling). Typically two replicate sampling sites were picked per outing to capture atmospheric variability for a given condition. As depicted in Fig. 6, the goal of the sampling strategy was to produce more standard sampling sites, with fewer replicate sampling sites and even fewer intensive sampling sites. This was based upon the approximate amount of time to acquire each sample and the limited amount of time to collect samples overall.

Field campaigns were deployed in the Marcellus Shale spanning northeast and southwest Pennsylvania. In total, 940 well pads were sampled with standard sampling, 53 with replicate sampling and 16 sites with intensive sampling. These replicate sampling sites were generally chosen at the beginning and end of each $4 \mathrm{~h}$ sampling period to observe changes in variability over the course of the sampling period that may be due to changes in atmospheric conditions. For the population of standard sampling sites with multiple passes, the average rsd of emissions from repeat passes was 


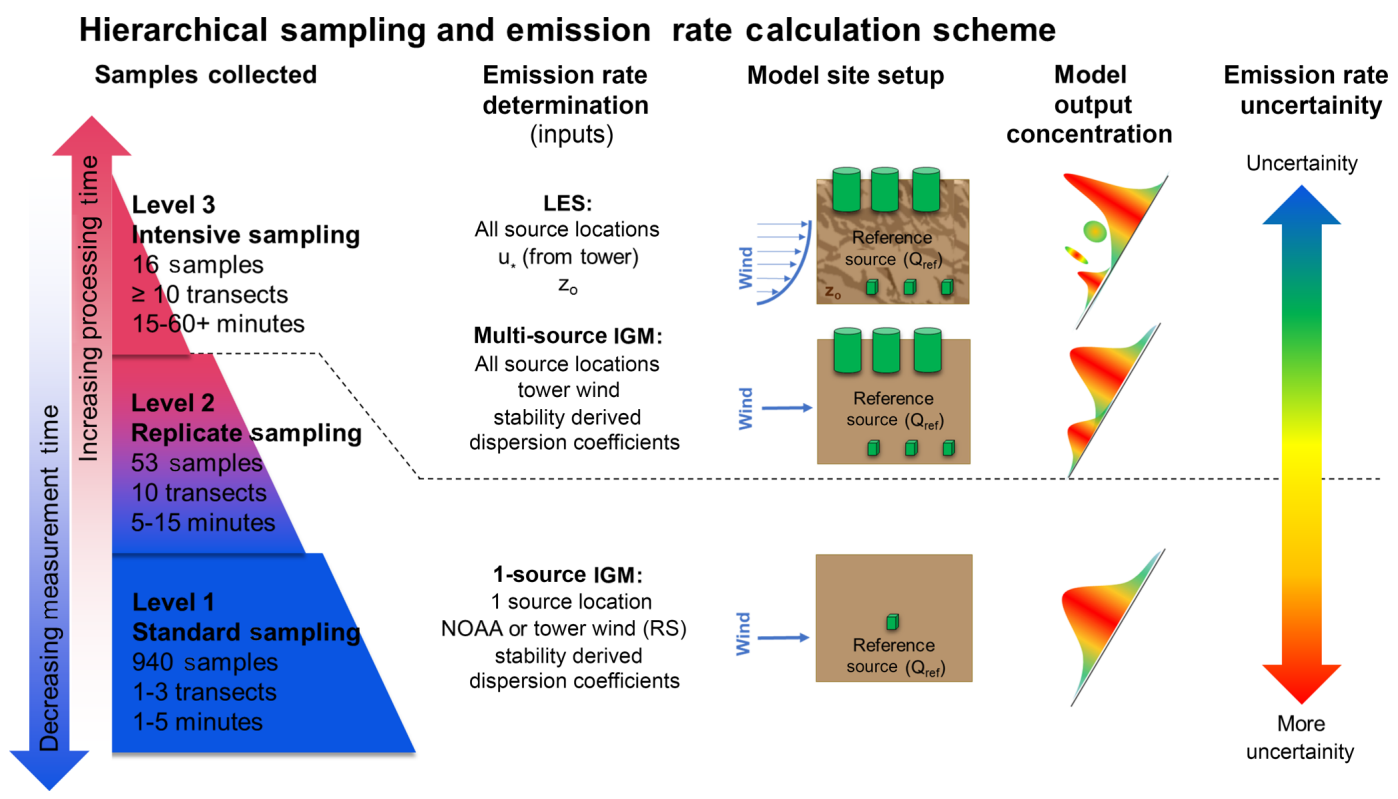

Figure 6. Finalized sampling and emission rate calculation strategy employed in this study showing actual measurements with increasing complexity and decreasing sample size as well as models with increasing complexity and decreasing uncertainty. The second column denotes user inputs needed for each pathway, with different pathways needing more or less inputs and different types of inputs. For instance, the stability-derived dispersion coefficients are necessary for level 1 and 2 , but not level 3 . In this schematic $u *$ is friction velocity and $z_{o}$ is terrain roughness length. The dashed lines denote the pathways data typically followed. Standard and replicate sampling always went through a single-source (1-source) IGM pathway. Note that the 1-source IGM can also be calculated for intensive samples as is shown for comparison purposes in this work. Abbreviations: LES (large eddy simulation), IGM (inverse Gaussian method).

$67 \%$ and the average maximum percent difference (highest observational deviation from the mean of repeat measurements) between emission estimates at a single site was $58 \%$. The average rsd of the population of 53 emissions estimates for the replicate sampling sites was $77 \%$ and the average maximum percent difference was $150 \%$. The rsd of emissions from repeat passes ranged from $12 \%$ to $260 \%$. These populations offer insight into how sampling strategy may change estimates of these statistics and offer the chance to compare real results to the LES results shown in Sect. 3.1. These results are consistent with the LES results shown in Sect. 3.1 predicting small numbers of transects will yield an artificially low rsd and more transects are needed to produce an accurate measure of variability. Additionally, the lower maximum percent difference for standard sampling is consistent with the Sect. 3.1 LES results showing few transects will sample more similar plume structures. While there is a large range in the rsd observed, $\sim 75 \%$ had rsd values less than $100 \%$.

\section{Results of source strength determination}

\subsection{Strategy for comparing LES and IGM results}

Comparisons between the IGM-calculated emission rates and LES output should be done with care because the LES cannot be scaled to different distances and wind angles easily. The base scenario for the Gaussian method at all sites (described in Sect. 2.3) assumes there is only one source at the $1 \mathrm{~m}$ elevation well-head location because the well head is the only geolocated structure in a public database and is the only structure common at every site. Sites may have varying numbers of well heads, but they are generally very close together $(<10 \mathrm{~m})$ so a centralized point is used for sites with multiple well heads. However, the Gaussian method can in fact be adjusted to include multiple sources and source heights. In order to ensure that the differences between outputs are due to the calculated model diffusion and not differences in model setup, we compare three scenarios: (i) the base scenario is the IGM approach used for all sites that assumes there is a singlesource Gaussian plume at the well head at $1 \mathrm{~m}$ (SS Gaussian), (ii) the second scenario assumes the sources are other structures on the domain (i.e., storage tanks and processing equipment) that are taller and uses a multi-source Gaussian plume (MS Gaussian) model where all sources have the same strength and (iii) the LES that simulates sources at the same locations and heights as the MS Gaussian. A schematic of the emission rate calculation strategy is shown in Fig. 6. Generally, the more information available (e.g., source location), the less uncertain the results are likely to be. Results will be compared from different scenarios to address to what extent uncertainty can actually be reduced. As on-site access was not available and well pads may contain multiple sources, all 

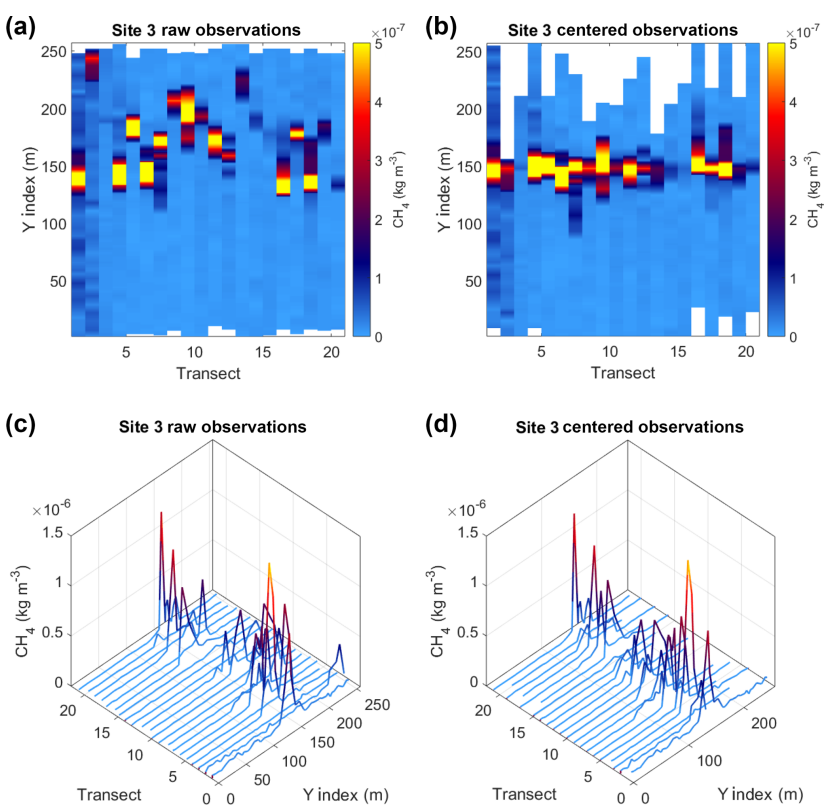

Figure 7. (a) Site 3 raw observations as indexed to the LES domain and (b) after they have been aligned with the peak of the LES plume. Waterfall plots of the same data for (c) raw observations and (d) centered observations.

large structures were treated as separate point sources. These were visually identified during measurements and exact coordinates were confirmed in Google Earth. The center of all sources was used as a point source. The identified sources were always gas processing units or storage tanks.

To compare to the LES results, the observations were indexed to coordinates on the 256 by $256 \mathrm{~m}$ horizontal LES grid. The resulting transects were interpolated within the range of observations to account for grid cells with multiple data points or missing data points. The LES time series spanning $\sim 30 \mathrm{~min}$ were averaged to produce a pseudoGaussian distribution excluding a $\sim 5 \mathrm{~min}$ initialization period (time until stationary state is achieved). LES statistics (mean and standard deviation of the scalar and wind components) were plotted as a function of time to determine the onset of a steady state (Fig. S2). Because all LES runs are nondimensionalized, the LES output needs to be scaled to represent the actual field conditions for a given observation. The LES non-dimensional and dimensionalized (denoted with a superscript D) outputs can be related by Eq. (3), which can be inferred from the stationary advection-diffusion equation or by analogy to the scaling of the Gaussian model in Eq. (1):

$\frac{C_{\mathrm{LES}}}{\dot{M}_{\mathrm{LES}}} \times u_{\mathrm{LES}}=\frac{C_{\mathrm{LES}}^{\mathrm{D}}}{\dot{M}_{\mathrm{LES}}^{\mathrm{D}}} \times u_{\mathrm{LES}}^{\mathrm{D}}$

Rearranging Eq. (3), the LES non-dimensional scalar output $\left(C_{\mathrm{LES}}\right)$ was dimensionalized $\left(C_{\mathrm{LES}}^{\mathrm{D}}\right)$ to units of $\mathrm{kg} \mathrm{m}^{-3}$ ac- cording to Eq. (4):

$C_{\mathrm{LES}}^{\mathrm{D}}=\frac{\dot{M}_{\mathrm{LES}}^{\mathrm{D}}}{\dot{M}_{\mathrm{LES}}} \times \frac{u_{\mathrm{LES}}}{u_{\mathrm{LES}}^{D}} \times C_{\mathrm{LES}}$.

Here, $\dot{M}_{\mathrm{LES}}^{\mathrm{D}}$ is the normalized mass $\left(1 \mathrm{~kg} \mathrm{~s}^{-1}\right)$ and $\dot{M}_{\mathrm{LES}}$ is the actual emission rate introduced into the LES system. Normalizing by $\dot{M}_{\text {LES }}$ is necessary to match the reference emission rate $\left(Q_{\text {ref }}\right)$ also used in the Gaussian method retrievals. The non-dimensional wind speed $\left(u_{\mathrm{LES}}\right)$ is divided by the dimensionalized $\left(u_{\mathrm{LES}}^{\mathrm{D}}\right)$ wind speed, which is set equal to the on-site tower measurements at the measurement altitude. The LES-generated winds thus retain a vertical wind profile. The peaks of the interpolated filed observations were centered to align with the peak location of the LES average plume as shown in Fig. 7; as previously discussed LES does not replicate the small changes in wind direction that can occur in the real world that cause meandering (unless they are known and imposed). The LES scaled concentration at $3 \mathrm{~m}$ (the mobile lab measurement height) was treated as $C_{\text {Model }}$ in Eq. (2) to produce LES-derived emission rates. This methodology is used to calculate the LES emissions shown in Sect. 4.3 and 4.4.

\subsection{Clarification of "meandering" and a conceptual proof of plume centering}

As terminology in boundary layer meteorology can be ambiguous and is not always used consistently, the specific meaning of "meandering" is discussed here in the context of the near-field regime applicable to this work. Many previous boundary layer works have used "meandering" to describe the general movement of a plume that does not correspond to the time-averaged profile, meaning it includes all scales of motion (see Venkatram and Wyngaard, 1988). However, Gaussian models do not simulate large-scale meandering or shifting wind directions unless these are included in the diffusion coefficients. Thus, we clarify that large-scale meandering as used in this work corresponds to the effect of larger $(\gg$ plume diameter) scale motions $(>\sim 100 \mathrm{~m})$. For instance, Seinfeld and Pandis (1998) acknowledge that plumes diffuse more with increased averaging time, which is in line with the previously discussed Fritz et al. (2005) work that observed there are optimum timescales to match a plume horizontal dispersion profile to the modeled output and observations can be quite different if their timescales are longer or shorter. The larger-scale motions would be responsible for creating a broader mean plume, but do not diffuse the instantaneous plume cross section (since they are larger than the plume's diameter). As discussed earlier, the size of eddies important for vertical diffusion is on the order of the source height; consequently, we also assume that larger-scale motions do not affect the vertical profile. Deardorff and Willis (1988) suggested that the downwind plane could be redefined every $20 \mathrm{~min}$ to remove larger mesoscale and synoptic-scale motions. 

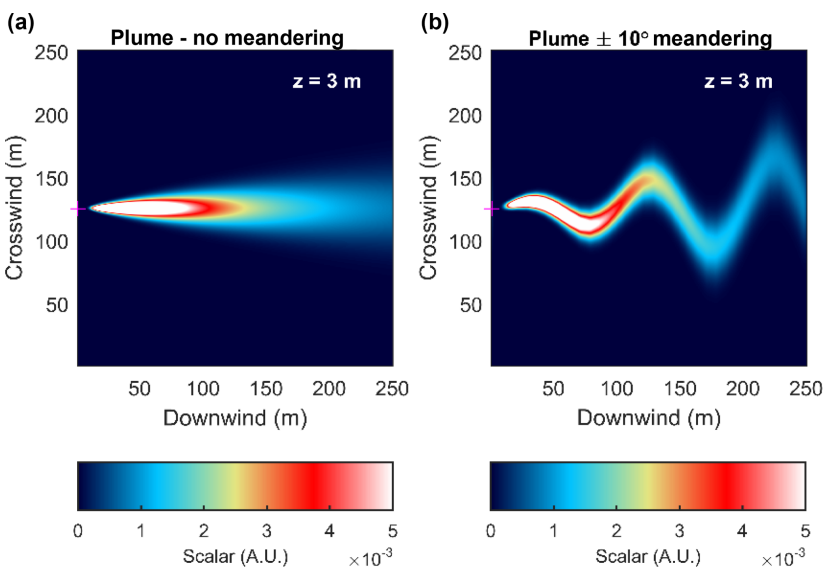

(c) Horizontal distribution ( $x=100 \mathrm{~m}, \mathrm{z}=3 \mathrm{~m}$ )

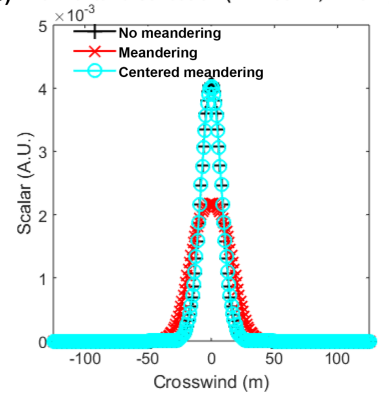

(d) Vertical distribution $(x=100 \mathrm{~m})$

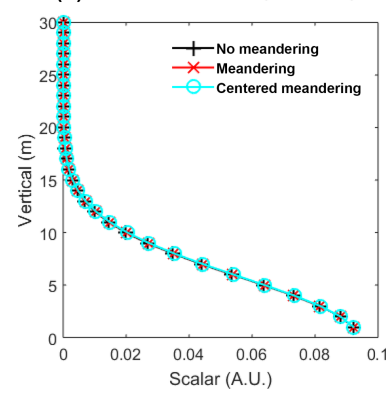

Figure 8. A theoretical site with an additional plume meandering scale added shown in a top-down view at $3 \mathrm{~m}$ of the (a) Gaussian plume with no meandering and (b) instantaneous Gaussian plume with $10^{\circ}$ meandering. The comparison of (c) horizontal distributions of concentration and (d) vertical distributions of concentrations for three scenarios (no meandering, averaged meandering and centered meandering) are also shown. All units are arbitrary.

As a conceptual exploration of the effects of the centering of the Gaussian model on individual plumes (as described in Sect. 2.3), a simulated meandering plume with a $100 \mathrm{~m}$ period and $10^{\circ}$ wind shift was investigated. The simulated plume and a comparison of a single Gaussian plume are shown in Fig. 8a, b. Using a $100 \mathrm{~m}$ downwind transect, the reconstructed plume, created by averaging the re-centered individual components, is compared to the Gaussian model with an average wind direction and the average of all the meandering profiles. As shown in Fig. 8c, d, the exact horizontal plume structure is duplicated simply by re-centering and averaging the individual plume realizations and the vertical plume structure is always preserved, whether additional meandering is included or not. When calculating emission rates using the IGM approach in this work, the instantaneous Gaussian plumes centered to the observations are used, instead of using a single average Gaussian profile. However, while the individually calculated emission rates can vary when using the aligned or average of the aligned Gaussian plumes, the differences are expected to be small.
To investigate whether the difference between the approaches would lead to a significant bias, the results for the controlled release experiments were compared for three approaches: the Gaussian plume centered on each observation that we have employed, the average of the individually simulated Gaussian profiles for multiple observations and a single Gaussian plume that matches the apparent average wind direction (Fig. S3). The results show that all three scenarios are virtually identical. Additionally, the centering of the Gaussian model on the observed plume is expected to be more suitable as suggested by the standard deviations that are $0-20 \%$ lower than results that rely on a single average Gaussian plume. This is likely due to the occurrence of wind conditions that are not symmetrical about the centerline and road geometries that allow for plumes of closer and farther distances. This centering can be thought of as a correction for the apparent conditions not matching ideal conditions in which a single Gaussian plume in the mean wind direction is theoretically appropriate. Yacovitch et al. (2015) also employed Gaussian plume centering to observations on the assumption that the source location was better constrained than the wind direction. Foster-Wittig et al. (2015) explored a similar concept of applying corrections to their methodology, which is based on the EPA OTM 33A protocol (U.S. EPA, 2014), to account for conditions that did not match the assumptions of the EPA protocol. They also observed that the differences between their methods were small. Overall, we expect uncertainty from the methodology we have employed to be constrained by the analysis present here, including using Gaussian model and LES outputs that are not varied based on the observed peak location. It should be noted that this centering may not always be necessary or optimal based on the specific goal of a campaign that might include source localization or atmospheric dispersion quantification.

When centering the observations to the LES (which cannot be modulated to match apparent changing wind direction in the way the Gaussian model can) the sum of the horizontal ( $y$ ) distribution is conserved, whether the observations are centered or not. This means that the emission rate does not change, whether centering or not centering the observations. The only potential for deviation is caused by moving part of the observations outside the imposed $256 \mathrm{~m}$ window during centering. The plume centering that we have chosen to apply to the observations is, in this case, expected to correct for the large-scale plume meandering not simulated in the LES and will not affect the calculated results; it is a way to filter out the meandering impact of the large scales in the field observations. Filtering observations for the purpose of matching the domain on the LES is also discussed by Agee and Gluhovsky (1999a, b) and Horst et al. (2004). Agee and Gluhovsky (1999a, b) specifically address the need to remove the influence of larger scales from observations to appropriately compare observations to the LES results. Finally, it is important to highlight that the integrated plume is used to calculate emissions, which mitigates the potential for con- 

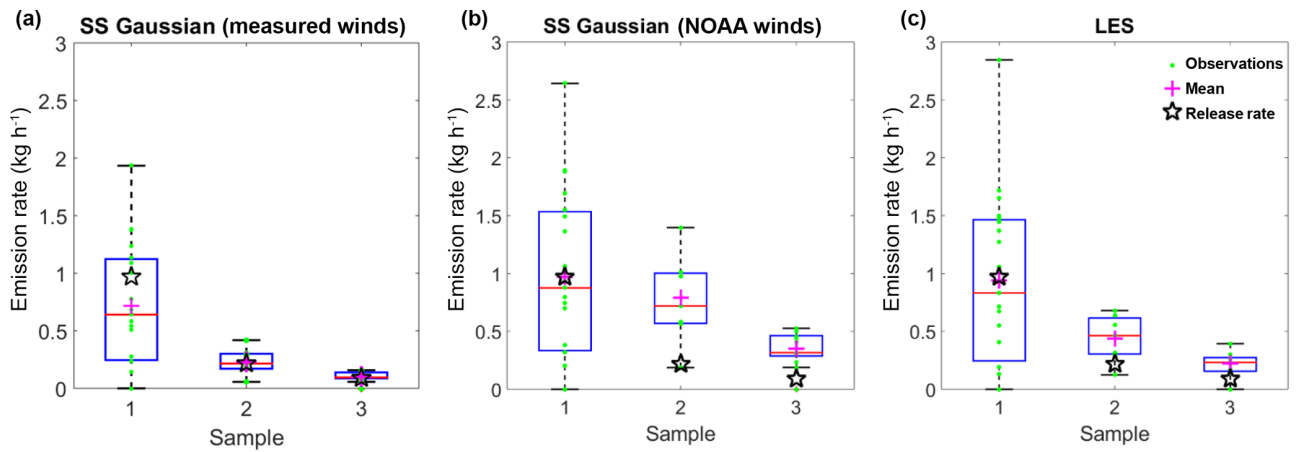

Figure 9. Results from three controlled release experiments for (a) the Gaussian approach using tower-measured winds, (b) the Gaussian approach using NOAA winds and (c) from the LES. Box and whiskers plots show the 50th percentile (red), 25th and 75th percentile (blue), and minimum and maximum values (black). The mean is shown in magenta, green dots represent individual measurements and the black star is the actual release rate. NOAA winds diverged from the measured winds significantly in releases 2 and 3 .

centration mismatch when comparing instantaneous plumes with structure to averages of LES or Gaussian model output due to averaging timescale differences. As noted in Albertson et al. (2016), the use of an integrated plume removes the influence of the random nature of the instantaneous plume, making this a beneficial procedure for these kinds of measurements.

\subsection{Controlled release}

The controlled release experiment (Site 5) utilized three leak rates: $0.97 \pm 0.01,0.216 \pm 0.002$ and $0.090 \pm 0.002 \mathrm{~kg} \mathrm{~h}^{-1}$. Release rates were controlled by two MKS mass flow controllers with a stated flow accuracy of $1 \%$ of the set point (model GE250A) or 0.05 standard liters per minute (model 1179C). Site setup was discussed in Sect. 2.2 and specific site details are available in Table 3. Due to the low height of the release, the LES domain was modified to have vertical resolution of $0.2222 \mathrm{~m}$ with a total domain height of $33.33 \mathrm{~m}$. Box plots of the populations of emission retrievals from three scenarios (SS Gaussian with NOAA winds, with measured winds and LES) are shown in Fig. 9 and statistics are summarized in Table 4. Figure 9a shows the emission rates using NOAA winds while Fig. 9b shows the emission rates calculated with measured wind. The two Gaussian method retrievals are shown to compare using NOAA winds, which is the base scenario for all sites, and using the in situ measured wind. Since the controlled release used one release point, there is only one source at a known height and the SS Gaussian approach is used. The agreement increases greatly when using the in situ wind data; NOAA overestimated the winds during the latter two release rates.

The Gaussian method approach with in situ measured wind agrees quite well with the release, surprisingly better than the LES. This may be due to the effects of stability the Gaussian model can account for, but they were not simulated in the LES where neutral conditions were assumed; this will be further discussed in Sect. 5.1. In this case, the conditions shifted from slightly unstable to neutral during the second release, with the friction velocity (an important scaling parameter for LES) decreasing from 0.21 to $0.10 \mathrm{~m} \mathrm{~s}^{-1}$. The slightly better performance of the Gaussian method in the experiment suggests that the correction factors for stability are at least as important an input as the direct calculation of diffusion in LES across a dynamic environment. While the LES investigation is useful to assess sources of error induced by sampling strategy, a controlled release is the most direct way to detect sources of bias, which otherwise would not be apparent. In general, the close agreement across a range of release rates shows no apparent bias in the Gaussian method with measured winds results, with the results scattered low and high relative to the release rate and no results significantly different (at the $95 \% \mathrm{CI}$ ) from the release rate. The Gaussian model with NOAA winds showed no bias when the winds matched with the observations as in the first sample, but may have biases if the winds are not well represented. The wind speeds measured (and NOAA winds) for releases $1-3$ were $3.0 \mathrm{~m} \mathrm{~s}^{-1}\left(4.1 \mathrm{~m} \mathrm{~s}^{-1}\right), 1.91 \mathrm{~m} \mathrm{~s}^{-1}\left(4.5 \mathrm{~m} \mathrm{~s}^{-1}\right)$ and $1.5 \mathrm{~m} \mathrm{~s}^{-1}\left(5 \mathrm{~m} \mathrm{~s}^{-1}\right)$, respectively. While LES can readily account for unstable or stable conditions, this would come at an increased computational cost as multiple simulations would be needed. The results here show that this in fact may not be necessary, at least over flat homogeneous terrain, as the Gaussian model provides a comparable performance at a very small fraction of the modeling effort.

The controlled release was also used as an observational constraint to investigate the sampling strategy identified by the LES. This was done by randomly selecting an increasing number of transects from each release and comparing the inferred mean release rate using the IGM. The results in Fig. 10 are in excellent agreement with the LES results pattern seen in Fig. 5, where the average converges beyond 10 transects. Note that the box plots correspond to the distribution of means obtained from randomly selecting the indicated number of transects, not total uncertainties on the means for 
Table 4. Summary of mean emissions from three scenarios for the controlled release ( \pm 1 standard deviation of the mean).

\begin{tabular}{lrrr}
\hline Scenario & Release $1\left(\mathrm{~kg} \mathrm{~h}^{-1}\right)$ & Release 2 $\left(\mathrm{kg} \mathrm{h}^{-1}\right)$ & Release 3 $\left(\mathrm{kg} \mathrm{h}^{-1}\right)$ \\
\hline Release rate & $0.97 \pm 0.01$ & $0.216 \pm 0.002$ & $0.090 \pm 0.002$ \\
No. of transects & 19 & 10 & 13 \\
Gaussian with NOAA winds & $0.97 \pm 0.17$ & $0.79 \pm 0.13$ & $0.35 \pm 0.04$ \\
Gaussian with measured winds & $0.72 \pm 0.12$ & $0.23 \pm 0.04$ & $0.10 \pm 0.01$ \\
Large eddy simulation & $0.94 \pm 0.17$ & $0.44 \pm 0.06$ & $0.22 \pm 0.03$ \\
\hline
\end{tabular}

(a)

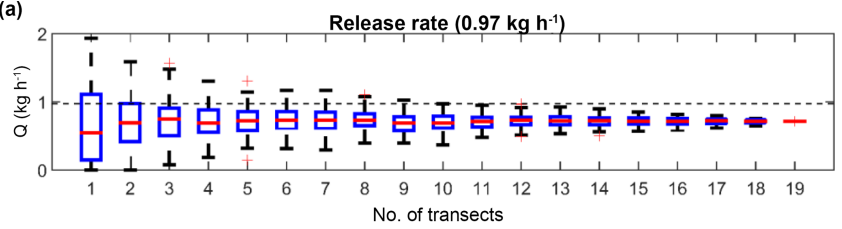

(b)
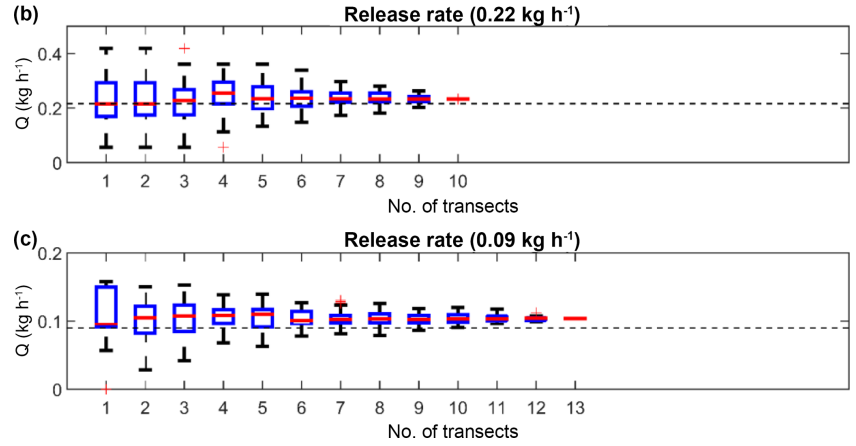

Figure 10. A comparison of the convergence of the mean plume rate inferred from the IGM by averaging randomly selected transects for (a) the $0.97 \mathrm{~kg} \mathrm{~h}^{-1}$ release rate, (b) the $0.22 \mathrm{~kg} \mathrm{~h}^{-1}$ release rate and (c) the $0.09 \mathrm{~kg} \mathrm{~h}^{-1}$ release rate. The actual release rate is shown as a dashed black line. Box and whiskers plots show the 50th percentile (red), 25th and 75th percentile (blue), and minimum and maximum values (black) of the means obtained for each number of transects. Outliers are shown in red.

each number of transects. This reiterates the importance of the sampling protocol and also shows the range of results possible if only a limited amount of transects are used. Additionally, Fig. 10 shows that the IGM rarely overestimates ( $>2 \times$ average release rate), but more often underestimates $(<0.5 \times$ average release rate). By this definition the IGM results underestimated the release rate by up to $30 \%$ of the time during the release rate using only $1-5$ transects. During release 1 and 3, even though a constant source is being emitted, a few (1-3) transects showed no observed plume whatsoever.

\subsection{Intensive field sites}

Comparisons between mean emission rates calculated from all available transects for sites 1-4 are shown in Table 5 and site-specific details are shown in Table 3. Relatively good agreement is found between the LES emission retrieval and the SS and MS Gaussian approach for sites 1-4. This indicated there is consistency in retrieved emissions from a range of scenarios despite using different amounts of information to set up the sources. The range of emission retrievals vary within a factor of 2 in most cases. For sites $1-4$, the average percent difference (difference from average value) between the LES and IGM emissions (SS or MS) was $\sim 25 \%$. Due to the effort to standardize the comparison between all approaches by centering and correcting the observations, the difference in emission is entirely due to the difference in the dispersion each model produces. The Gaussian models assume stability-corrected diffusion coefficients from Briggs (1973) while the LES makes no assumptions and allows turbulence to be numerically solved. The LES, however, was only run under neutral stability in this study. As shown in Fig. 11, the horizontal dispersion generally matches well between the LES and the MS Gaussian, while the vertical dispersion exhibits slightly different behavior. In the sites studied the LES predicts peak vertical flux (obtained by multiplying mean concentration $\times$ mean wind speed) at lower altitudes closer to the source and at higher altitudes farther from the sources with the equivalence point around $100 \mathrm{~m}$ downwind (additional figures of Gaussian model and LES dispersion are shown is Figs. S5S7). The differences are due to the distance scaling in the Briggs (1973) model being different from the LES. While there are other analytical models for distance-specific dispersion coefficients, the Briggs (1973) model actually matches the LES profiles better across the range of sites explored here than several other common models (Gifford Jr., 1976; Smith, 1968; see Figs. S8-S11 and Appendix A). Vertical dispersion is generally more important than the horizontal dispersion as integrating across a transect will effectively nullify any differences resulting from horizontal diffusion. However, if a difference in vertical dispersion exists, this can significantly change the retrieved emission rate. There is considerable difference between the SS and MS results, for instance. Without observations at multiple heights, it is impossible to verify which assumption is correct. However, the SS results are typically closer to the LES results in these simulations, suggesting that this is the better approach compared to assuming source height and locations. In the range of distances investigated in this study $(<200 \mathrm{~m})$ the overall discrepancy between the different model outputs is, however, small. 


\section{Site 3}
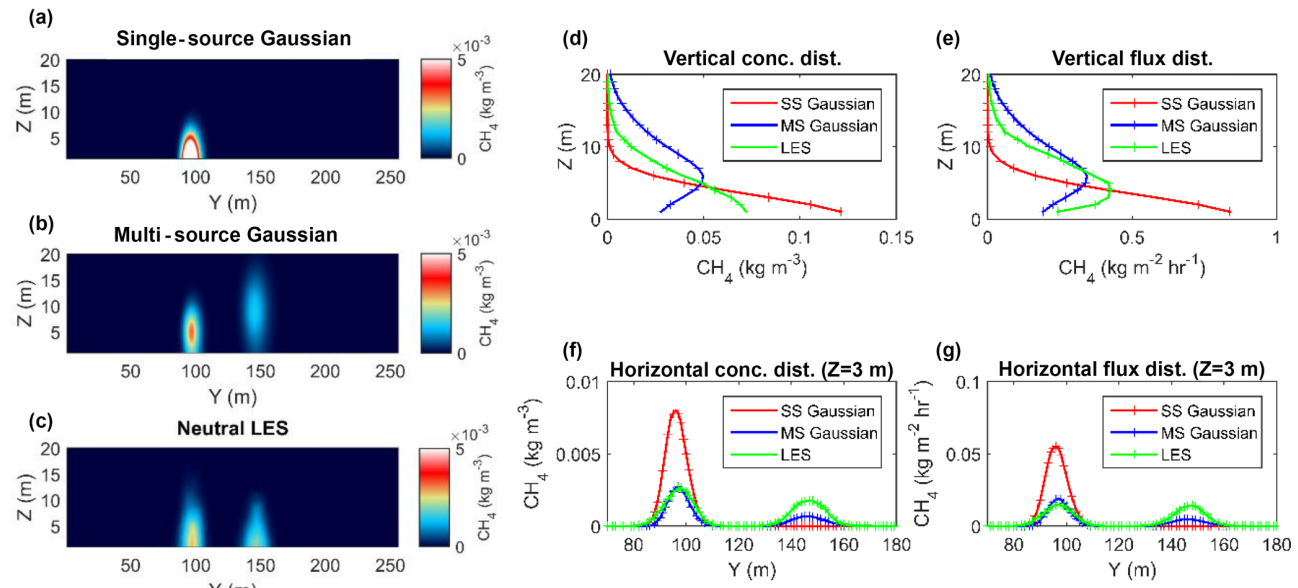

Figure 11. Comparison of three scenarios for Site 3 showing images through the downwind road plane ( $\sim 30 \mathrm{~m}$ downwind as shown in Fig. 3 ) of (a) single-source Gaussian, (b) multi-source Gaussian and (c) averaged LES. The comparison of vertical distributions of (d) concentrations and (e) fluxes and of the horizontal distributions of (f) concentrations and (g) fluxes are also shown. The vertical LES flux corresponds to resolved fluxes only.

Table 5. Comparison of mean emission rates using three scenarios from four sites ( \pm 1 standard deviation of the mean).

\begin{tabular}{lrrrr}
\hline Scenario & Site $1\left(\mathrm{~kg} \mathrm{~h}^{-1}\right)$ & Site 2 $\left(\mathrm{kg} \mathrm{h}^{-1}\right)$ & Site $3\left(\mathrm{~kg} \mathrm{~h}^{-1}\right)$ & Site $4\left(\mathrm{~kg} \mathrm{~h}^{-1}\right)$ \\
\hline No. of transects & 26 & 28 & 21 & 22 \\
Single-source Gaussian & $1.0 \pm 0.3$ & $0.19 \pm 0.03$ & $1.09 \pm 0.16$ & $0.19 \pm 0.06$ \\
Multi-source Gaussian & $2.2 \pm 0.9$ & $0.24 \pm 0.06$ & $1.8 \pm 0.3$ & $0.29 \pm 0.06$ \\
Large eddy simulation & $1.5 \pm 0.4$ & $0.18 \pm 0.03$ & $0.76 \pm 0.11$ & $0.18 \pm 0.03$ \\
\hline
\end{tabular}

\section{Uncertainty analysis and discussion}

\subsection{Other uncertainty source}

For this analysis, we have assumed the source to be constant during the time span of the measurements (typically less than $1 \mathrm{~h})$. This may not be true for all sites and may be a driver of variability; for instance, tanks are known to emit sporadically and Goetz et al. (2015) have shown emissions varying over the course of a few hours. However, it is not clear that there is a need to quantify emission variability at scales less than $1 \mathrm{~h}$ for most sources as there is a practical limit to the time resolution that can be included in inventory estimates. We thus expect any changes in emission rate at $<1 \mathrm{~h}$ to be reflected in what we have termed atmospheric variability, or transect to transect variability.

Other sources of uncertainty considered are source location and source height. While well pads can be a few thousand $\mathrm{m}^{2}$ in area, infrastructure that could generate leaks is usually clustered such that observed potential sources span a range of $50 \mathrm{~m}$. This can be investigated theoretically by comparing the expected model sum as a function of distance assuming a $50 \mathrm{~m}$ shift in source location as shown in Fig. S12. This scenario assumes typical conditions observed in this dataset ( $3 \mathrm{~m}$ receptor height, $1.5 \mathrm{~m} \mathrm{~s}^{-1}$ wind and neutral stability). Generally, changing the along-wind location of the sources changes the emission retrieval by less than $35 \%$ when measuring at $>100 \mathrm{~m}$ downwind. However, at closer distances where the uncertainty in source location is on the order of the downwind distance this could be a major source of error. For reference, the median distance between observation and sources in this dataset is about $200 \mathrm{~m}$ with no sites closer than $30 \mathrm{~m}$ and only five sites less than $50 \mathrm{~m}$. At $200 \mathrm{~m}$ uncertainty is expected to be $\sim 20 \%$. We also investigated the sensitivity of source height, which we estimate ranges from $1 \mathrm{~m}$ for wellheads to $8 \mathrm{~m}$ for some large storage tanks, as shown in Fig. S13. The results indicate that source height variation changes the emission retrieval by less than $15 \%$ at downwind distances $\sim 200 \mathrm{~m}$, again due to the large distance from the source. Uncertainty of the source location in the crosswind direction is not expected to contribute to significant change in emissions.

Additionally, as shown in Sect. 4.1 (Fig. 9 and Table 4), inaccurate wind data can be a potential source of error. Because the modeled $\mathrm{CH}_{4}$ concentration scales with wind in both the Gaussian and LES models, it is necessary to constrain the uncertainty in this parameter. In the context of this analysis, we compared the NOAA wind to the mean on-site tower mea- 
surements of winds at 16 tower sites. NOAA wind speeds reported higher and lower values than the mean measured winds; the absolute difference was $50 \%$ on average. Given the linear relationship between the inverse of wind speed and $Q$ in the Gaussian equation (Eq. 1), relative uncertainty in the wind speed should produce the same magnitude relative uncertainty in the emission rate.

Another important consideration is the assignment of the background value to calculate plume enhancement. For this work, the background was calculated as the minimum value from the plume transect because the averaged $1 \mathrm{~Hz}$ data generally showed a uniform background near the plumes. These criteria were also compared to a scenario where the background was calculated from the average of the lowest $2 \%$ of observations in a transect with very similar results again indicating that the background value is very stable. When comparing samples with repeat transects, the backgrounds identified for each transect had a median standard error of $5 \mathrm{ppb}$. When the $5 \mathrm{ppb}$ tolerance is applied to the same dataset, the median change in calculated flux was $4.4 \%$. This means that the background is expected to contribute an additional $\sim 5 \%$ uncertainty. It should be noted, however, that for very low signals the background can become a major source of uncertainty. The average peak enhancement was $\sim 1250 \mathrm{ppb}$ with a median value of $\sim 260 \mathrm{ppb}$. Sites with enhancements less than $50 \mathrm{ppb}$ were identified as having emissions that were indistinguishable from zero, when considering all other sources of error. These data were designated as non-emitting sites in the emission database.

The final additional source of uncertainty investigated pertains to stability. The stability class determines the analytical equation used to derive the diffusion coefficients, thus affecting the emission rate. By again comparing a theoretical case, the effect of changing the stability class by 1 can be seen in Fig. S14. The tolerance of 1 stability class reflects the fact that the atmosphere does not usually change multiple stability classes rapidly at a scale of 1-3 h (i.e., a change from class A to class $\mathrm{E}$ would not be feasible). While there are certainly cases where the atmosphere can change rapidly in this time period (i.e., from class B to D), generally a miscategorization class difference of at most 1 is expected. For instance, neutral stability was targeted (Class D) for the $\sim 1000$ sites measured as part of this work. Class D was the most frequent stability class observed, with $90 \%$ of the data occurring between \pm 1 stability class. Making the stability class less stable will decrease the modeled concentration and consequently increase the emission retrieval, while making the stability class more stable will have the opposite effect. The magnitude of the difference between \pm 1 stability class is relatively consistent at a farther downwind distance, averaging a change of $40 \%$ at $200 \mathrm{~m}$ downwind.

Not investigated here, but potentially very important to uncertainty, is the effect of terrain including both nonuniform slopes and structures such as trees. In this analysis, we have intentionally sampled sites that were determined to be rela- tively flat and open. All of the sites modeled in this study follow these criteria, even though not every site in our sample is as simple. The geometric mean of the absolute terrain slope, defined as the absolute value of terrain rise over the distance between sources and observation, for all of our $\sim 1000$ sampled sites was $3 \%$, and $\sim 60 \%$ of the sites sampled had an absolute terrain slope of less than $5 \%$. Nevertheless, some sites did contain more complex topography that could cause drastically different dispersion parameters. Such sites would need to be analyzed on a case by case basis as dispersion over complex topography is usually not generalizable because every site is unique (e.g., the inverse Gaussian modeling approach might work very well at one site but poorly at another). This analysis would be nontrivial and requires high-resolution topography data, surface heat flux fields and many other inputs for accurate modeling. Another possible pathway to fully investigate the effects of terrain is to investigate the correlation between site emissions determined using Gaussian models and terrain slope. From these analyses one can determine screening criteria to preserve data quality and examine the skill of Gaussian models over complex terrain in general. This is the subject of forthcoming work using the larger dataset and not discussed here. A final note on this topic is that the present LES represented the tanks and structures of the sites as bluff bodies that blocked the flow and created wakes, while the Gaussian models did not. This did not result in a drastic difference between the Gaussian method and LES results, indicating that perhaps small obstructions do not have a disproportionate impact on the retrieved emission rates.

\subsection{Total uncertainty estimate}

The sources for uncertainty and bias in the Gaussian method measurements discussed in this analysis are summarized in Table 6. These include the uncertainty in the Gaussian model diffusion constant by comparing to LES-calculated diffusion (Sect. 4), uncertainty due to source location and height, and uncertainty due to wind speed and stability class (Sect. 5.1). In addition, the LES was used to observe bias in the Gaussian-model-derived concentration distributions (Sect. 4.4) and the controlled release was used to evaluate bias in both the Gaussian method and LES results (Sect. 4.3). Finally, the LES was used to determine the optimum sampling pattern to constrain actual atmospheric variability (Sect. 3.1 and 3.2). The largest contributor to total uncertainty is atmospheric variability, the random error induced by insufficient averaging of the turbulent instantaneous plume. As atmospheric variability is impossible to separate from other sources of uncertainty, such as wind speed, it is not surprising that it is the largest source of uncertainty. As described in Sect. 3.1, the LES-derived atmospheric variability (defined as the standard deviation of emissions retrieved) is expected to be $\sim 25 \%$, considerably less than the standard deviation observed directly since the LES can capture 
Table 6. Sources and magnitude of uncertainty in IGM emission estimates.

\begin{tabular}{llr}
\hline Uncertainty source & Notes & $\begin{array}{r}\text { Expected } \\
\text { uncertainty }\end{array}$ \\
\hline Atmospheric variability & $\begin{array}{l}\text { Requires } \geq 10 \text { transect to quantify, not independent } \\
\text { from other uncertainty sources }\end{array}$ & $77 \%$ \\
Instrumental uncertainty $^{2}$ & LI 7700 expected 1Hz precision of 1.6 ppb & $<1 \%$ \\
Plume turbulent diffusion $^{2}$ & Potentially source of uncertainty and bias & $25 \%$ \\
Source height $^{3}$ & $Z$ uncertainty low at distances $>150 \mathrm{~m}$ & $15 \%$ \\
Source location $^{3}$ & Combined $x$ and $y$ uncertainty low at distance $>150 \mathrm{~m}$ & $20 \%$ \\
Stability $^{3}$ & Potential 1 stability class discrepancy & $40 \%$ \\
Wind speed $^{3}$ & Uncertainty scales linearly & $50 \%$ \\
Background $^{3}$ & Important for small concentration enhancements & $5 \%$ \\
\hline
\end{tabular}

${ }^{1}$ Derived in Sect. 3.2. ${ }^{2}$ Derived from the comparison of LES-calculated dispersion and IGM-modeled diffusion in Sect. $4 .{ }^{3}$ Derived in Sect. 5.1.

Table 7. Monte Carlo inputs for each uncertainty estimate.

\begin{tabular}{|c|c|c|c|c|c|}
\hline Uncertainty (assumed distribution) & SS Gaussian & MS Gaussian & SS Gaussian & MS Gaussian & Lower limit \\
\hline No. of transects & 1 & 1 & 10 & 10 & 1 \\
\hline $\begin{array}{l}\text { Source location in } x \text { direction } \\
\text { (Gaussian) }\end{array}$ & 1 sigma $=16.7 \mathrm{~m}$ & 1 sigma $=0$ & 1 sigma $=16.7 \mathrm{~m}$ & 1 sigma $=0$ & 1 sigma $=0$ \\
\hline Source height (uniform) & $1-8 \mathrm{~m}$ & $1 \mathrm{~m}$ & $1-8 \mathrm{~m}$ & $1 \mathrm{~m}$ & $1 \mathrm{~m}$ \\
\hline $\begin{array}{l}\text { Atmospheric variability in } \\
\text { observation (Gaussian) }\end{array}$ & $\begin{array}{r}1 \text { sigma }=100 \% \\
(260 \mathrm{ppb})\end{array}$ & $\begin{array}{r}1 \operatorname{sigma}=100 \% \\
(260 \mathrm{ppb})\end{array}$ & $\begin{array}{r}1 \text { sigma }=100 \% \\
(260 \mathrm{ppb})\end{array}$ & $\begin{array}{r}1 \operatorname{sigma}=100 \% \\
(260 \mathrm{ppb})\end{array}$ & $\begin{array}{r}1 \text { sigma }=25 \% \\
(65 \mathrm{ppb})\end{array}$ \\
\hline Wind speed (Gaussian) & $\begin{array}{r}1 \text { sigma }=50 \% \\
\quad\left(0.75 \mathrm{~m} \mathrm{~s}^{-1}\right)\end{array}$ & 1 sigma $=0$ & $\begin{array}{r}1 \text { sigma }=50 \% \\
\quad\left(0.75 \mathrm{~m} \mathrm{~s}^{-1}\right)\end{array}$ & 1 sigma $=0$ & 1 sigma $=0$ \\
\hline Stability $\quad$ (uniform) & $\mathrm{C}-\mathrm{E}$ & $\mathrm{D}$ & $\mathrm{C}-\mathrm{E}$ & $\mathrm{D}$ & $\mathrm{D}$ \\
\hline Background (Gaussian) & 1 sigma $=5 \mathrm{ppb}$ & 1 sigma $=5 \mathrm{ppb}$ & 1 sigma $=5 \mathrm{ppb}$ & 1 sigma $=5 \mathrm{ppb}$ & 1 sigma $=0 \mathrm{ppb}$ \\
\hline Uncertainty range $(95 \% \mathrm{CI})$ & $0.05-6.5 q$ & $0.08-3.2 q$ & $0.5-2.7 q$ & $0.6-1.6 q$ & $0.5-1.5 q$ \\
\hline
\end{tabular}

the effect of turbulence, but not the effect of changes in the mean flow and meandering plumes that can contribute significantly to overall atmospheric variability (Vickers et al., 2008; Mortarini et al., 2016). LES has a limited ability to represent the very large-scale motions (Kunkel and Marusic, 2006) or some eddy features (Glendening, 1996) due to its limited horizontal domain size and idealized forcing (e.g., de Roode et al., 2004; Agee and Gluhovsky, 1999a, b). In addition, the limitation of LES in the surface layer due to applications of the Monin-Obukhov similarity theory is also one of the concerns (e.g., Khanna and Brasseur, 1997). We do not intend to represent all sources of uncertainties pertaining to the atmospheric conditions. Instead, the focus of the LES is to resolve the range of scales that are critical for the turbulent diffusion of the plume, which is often represented as a single eddy diffusivity coefficient in the Gaussian plume models. Thus, the LES-predicted variability is the practical lower limit of uncertainty for this method since other sources of uncertainty could be mitigated by better on-site measurements and source location detection, but some random atmospheric variability is more difficult to constrain. While the higher observed atmospheric variability may be partially explained by far more complex real-world conditions leading to higher standard deviations, this also emphasizes the possibility that other sources of uncertainty are contained in this realization of atmospheric variability. For instance, most sites, while relatively flat, still have some inhomogeneous terrain that can influence and deflect wind or lead to increased turbulence. To combine the remaining sources of error, a Monte Carlo simulation of errors through the Gaussian equation was performed. Inputs are available in Table 7 and an example output in Fig. S15. This approach was determined to be the most appropriate as uncertainties may not be normally distributed and emissions are constrained to be above zero in this scenario, causing a skew to the emission retrievals. A generic scenario matching average conditions experienced during the measurements was devised using a downwind distance of $200 \mathrm{~m}, 1.5 \mathrm{~m} \mathrm{~s}^{-1}$ wind speed, neutral stability and a 260 ppb observation enhancement. The specifics with regards to distributions assumed for each uncertainty parameter are shown in Table 7 for the SS Gaussian and MS Gaussian approaches with 1 and 10 transects, as well as a theoretical lower limit scenario. For each scenario, 1000 randomly generated samples of $C_{\text {Observation }}, C_{\text {Background }}$ and $C_{\text {Model }}$ were obtained and used according to Eq. (2) to obtain a distribution of $Q$ samples. The $Q$ samples were then used to estimate 
the $95 \%$ confidence interval. The combined effects produce a skewed distribution of emission rates as shown in Fig. S15. Using this methodology we obtain an uncertainty range for single-transect emissions of $0.05-6.5 q$, where $q$ is the emission rate; for sites that had multiple passes and wind measurements (replicate and/or intensive) the range is $0.10-3.0 q$. As discussed in Sect. 5.1, this analysis focuses on relatively flat, simple sites and is not intended to be generalized to extremely complex sites. We caution that the plume diffusion uncertainty is therefore a minimum expected value and could be a major source of uncertainty for very complex sites not investigated here.

\subsection{Advantages and disadvantages}

Of the approaches compared in this analysis, the LES results require far more computational and processing time. Though inputs can be estimated from other sources (i.e., NOAA), we chose to measure meteorological variables directly, which contributed to significantly longer measurement time. While this should be considered best practice when producing computationally expensive LES outputs, there are no inherent differences between inputs needed for LES and Gaussian method approaches, and the Gaussian method approach also benefits from on-site measurements making in-field measurement time theoretically similar. In practice, the additional setup time for meteorological instrumentation can increase total measurement time for sites intended for LES to $>1 \mathrm{~h}$. Table 8 summarizes the main advantages and disadvantages for each technique. The main advantage of the LES is the ability to directly calculate the plume diffusion rather than rely on simplified models. However, the LES simulations shown here have all been initialized for neutral conditions, which is the stability class we targeted during sampling. This is a relatively transient atmospheric phase typically only occurring in the morning and evening around sunrise and sunset, and generally other stability classes are encountered. The Gaussian method enables easy corrections for different stabilities allowing quick processing of data collected in these regimes. While LES can be programmed with different stabilities, the additional computational cost is great and the surface energy budget must be known, which introduces another source of uncertainty as actual heat fluxes may vary over the domain of interest and single point measurements may not be accurate. For these reasons, LES alone would not be the recommended method of calculating emission rates based on our study. Likewise, the single-transect method, though fast, has many sources of uncertainty. Hence, the strategic combination of all of these approaches described in Sect. 3 is expected to maximize sampling efficiency while minimizing uncertainty. Less frequent higher-intensity measurements (from on-site meteorological data and multiple transects) can be used to provide a better estimate of uncertainty for single-transect approaches.

\section{Comparison to previous uncertainty estimates}

Overall, we find LES to be a useful tool to examine the Gaussian method sampling strategy and sources of uncertainty for mobile laboratory measurements. Subsampling the LES output generates an optimum sampling pattern of at least 10 transects per site to obtain reliable statistics of measurement uncertainty due to atmospheric variability, which is the largest source of uncertainty. When sampling at distances greater than $150 \mathrm{~m}$ downwind of sites, the uncertainty due to source location and height is generally less than $20 \%$ (for cases where source location is known within $50 \mathrm{~m}$ and source height is known within $10 \mathrm{~m}$ ). Using the LES and a controlled release, we confirm that the Gaussian model performs well when in situ winds are available. The NOAAestimated winds can be a source of error, but we did not observe a systematic difference between the NOAA and in situ winds; thus, no sources of bias using our approach are expected on average. We note that this result is valid for this general area, and other locations, which have different challenges and data density, may differ. Area-specific analysis, or on-site winds, should always be used to reduce bias. LES is therefore not required for studies where source strength calculation is the main goal and other complicating factors such as complex topography are not present. The emission retrievals generally fall within a range of two. From this we use Monte Carlo analysis to extrapolate that the $95 \%$ confidence interval for sites with standard sampling $(n=2)$ ranges from 0.05 to $6.5 q$, where $q$ is the emission rate. Using the same approach, sites that had multiple passes and wind measurements (replicate/intensive) can be further constrained to $0.10-3.0 q$. This uncertainty estimate is higher than Lan et al. (2015), who reported $0.5-1.5 q$ at the $95 \%$ confidence interval. Their study is identical to the theoretical lower limit of uncertainty we calculate by assuming only the LES predicted atmospheric variability of $25 \%$. It should be noted that Lan et al. (2015) did incorporate some averaging over a time frame of $>10 \mathrm{~min}$ into their measurements, which, as discussed in Sect. 5.3, can also decrease uncertainty. However, this would not mitigate all other sources of error previously discussed.

In addition, our standard sampling uncertainty range is greater than other Gaussian method approaches with controlled releases which reported $0.28-3.6 q$ and $0.334-3.34 q$ (Rella et al., 2015; Yacovitch et al., 2015); the uncertainty range of the multi-transect sites studies here was similar in magnitude $(0.05-6.5 q)$. However, their analysis did not account for additional sources of uncertainty (source location, stability, wind speed), which can result in uncertainties larger than the reported values. In addition, Rella et al. (2015) incorporated vertical information to inform their Gaussian plume model creating a mass balance Gaussian hybrid, though only a small vertical profile was available (four measurement points up to $4 \mathrm{~m}$ ). As the vertical flux was seen to be a potential source of error in this work, measurements of this 
Table 8. Summary of advantages and disadvantages of each technique.

\begin{tabular}{llll}
\hline & Measurement time & Processing time & Sources of uncertainty \\
\hline Single-transect Gaussian & $\begin{array}{l}\text { Short } \\
(<10 \mathrm{~min})\end{array}$ & $\begin{array}{l}\text { Short } \\
(\sim \text { few minutes })\end{array}$ & $\begin{array}{l}\text { Many sources, atmospheric } \\
\text { variability unconstrained }\end{array}$ \\
\hline Multi-transect Gaussian & $\begin{array}{l}\text { Moderate } \\
(15-30 \mathrm{~min})\end{array}$ & $\begin{array}{l}\text { Short } \\
(\sim \text { few minutes })\end{array}$ & $\begin{array}{l}\text { Atmospheric variability constrained, } \\
\text { diffusion unconstrained }\end{array}$ \\
\hline Multi-transect LES & $\begin{array}{l}\text { Moderate to long } \\
(15 \text { min }-1 \mathrm{~h})\end{array}$ & $\begin{array}{l}\text { Very long } \\
(\text { several days })\end{array}$ & $\begin{array}{l}\text { Atmospheric variability constrained, } \\
\text { diffusion constrained }\end{array}$ \\
\hline
\end{tabular}

metric may reduce uncertainty. As described in Sect. 3.2, the observed atmospheric variability (observed from transect to transect emission rate variability) can range from 10 to $200 \%$. Atmospheric variability (random error) was the single largest driver of uncertainty in the Monte Carlo simulations (see for example Fig. S15) because the model can be improved with better information and wind measurement. To reduce the uncertainty from atmospheric variability, more observations are needed; however, sometimes this is impractical. In situ observations of variability from repeat measurements at a single site may potentially be used as a postscreening method to exclude conditions that will lead to extremely high uncertainty in single-transect sites. Other factors such as wind speed and stability can have a strong effect and can be quantified to reduce uncertainty.

\section{Recommendations}

While the uncertainty derived for mobile Gaussian plume techniques is large compared to many other techniques discussed in Sect. 1, it is low enough to reliably separate normal emissions from extreme emissions that are orders of magnitude larger. Many emission sources exhibit lognormal distributions where this condition is met, making mobile sampling a reliable way to identify extreme emission sites. However, longer sampling time, reliable mobile wind sampling and visualization of plume distributions are needed to feasibly constrain this method to under $50 \%$ for routine measurements. In summary, to facilitate more constrained uncertainty from other mobile-platform-based Gaussian plume emission estimates, we recommend the following:

1. Sites should be isolated to reduce contamination from other sources and be accessible from thoroughfares at least $100 \mathrm{~m}$ away.

2. On-site wind measurement should be collected whenever possible.

3. Additional data should be collected such as photographs (used here) or IR imagery to precisely locate the sources whenever possible.
4. Ideally, all sites should use $\geq 10$ sampling transects to reliably constrain atmospheric variability.

5. For experiments where sampling frequency is at a premium, at least one site per sampling outing should be repeated with $\geq 10$ sampling transects to reliably constrain atmospheric variability, which is expected to be the largest source of the uncertainty estimate.

6. Uncertainty analysis should be a systematic part of the Gaussian method sampling design.

7. In the absence of other experiments to study measurement uncertainty (controlled releases), the repeat measurements may be a suitable approximation for the minimum expected uncertainty.

While the strategies described in the study (see Fig. 6) were developed for well pads, the recommendation may be applied to other point-like sources with simple terrain, appropriate scaling and no means of site access for other, potentially more accurate, methods. Examples may include (if far enough downwind to consider the source a point) compressor stations, feed lots, waste water treatment plants, landfills, natural gas pipeline leaks, industrial facilities, and geologic seeps and vents. While the scales involved may differ significantly from a well pad, the necessity for constraining atmospheric variability is critical toward understanding the uncertainties of inverse Gaussian-plume-derived emissions.

Data availability. A data file containing all the emissions, limit of detection, uncertainty estimate, meteorology, site locations and traits including spud date, operator, production and status is available from DataSpace at Princeton University (http://arks.princeton. edu/ark:/88435/dsp01wh246v90d, last access: 10 October 2018; Caulton and Zondlo, 2018). 


\section{Appendix A}

Table A1. Diffusion equations (m) as presented in Zannetti (1990).

\begin{tabular}{|c|c|c|c|c|c|}
\hline \multicolumn{6}{|c|}{ Briggs (1973) rural } \\
\hline Stability & Horizontal $\left(\sigma_{y}\right)$ & Vertical $\left(\sigma_{z}\right)$ & & & \\
\hline A & $0.22 x(1+0.0001 x)^{-0.5}$ & $0.20 x$ & & & \\
\hline B & $0.16 x(1+0.0001 x)^{-0.5}$ & $0.12 x$ & & & \\
\hline $\mathrm{C}$ & $0.11 x(1+0.0001 x)^{-0.5}$ & $0.08 x(1+0.0002 x)^{-0.5}$ & & & \\
\hline $\mathrm{D}$ & $0.08 x(1+0.0001 x)^{-0.5}$ & $0.06 x(1+0.0015 x)^{-0.5}$ & & & \\
\hline E & $0.06 x(1+0.0001 x)^{-0.5}$ & $0.03 x(1+0.0003 x)^{-0.5}$ & & & \\
\hline $\mathrm{F}$ & $0.04 x(1+0.0001 x)^{-0.5}$ & $0.016 x(1+0.0003 x)^{-0.5}$ & & & \\
\hline \multicolumn{6}{|c|}{ Briggs (1973) urban } \\
\hline Stability & Horizontal $\left(\sigma_{y}\right)$ & Vertical $\left(\sigma_{z}\right)$ & & & \\
\hline A & $0.32 x(1+0.0004 x)^{-0.5}$ & $0.24 x(1+0.001 x)^{0.5}$ & & & \\
\hline B & $0.32 x(1+0.0004 x)^{-0.5}$ & $0.24 x(1+0.001 x)^{0.5}$ & & & \\
\hline $\mathrm{C}$ & $0.22 x(1+0.0004 x)^{-0.5}$ & $0.20 x$ & & & \\
\hline $\mathrm{D}$ & $0.16 x(1+0.0004 x)^{-0.5}$ & $0.14 x(1+0.0003 x)^{-0.5}$ & & & \\
\hline $\mathrm{E}$ & $0.11 x(1+0.0004 x)^{-0.5}$ & $0.08 x(1+0.00015 x)^{-0.5}$ & & & \\
\hline $\mathrm{F}$ & $0.11 x(1+0.0004 x)^{-0.5}$ & $0.08 x(1+0.00015 x)^{-0.5}$ & & & \\
\hline Gifford (1961) & $\frac{k_{1} x}{\left[1+\left(\frac{x}{k_{2}}\right)\right]^{k_{3}}}$ & $\frac{k_{4} x}{\left[1+\left(\frac{x}{k_{2}}\right)\right]^{k}}$ & & & \\
\hline \multirow[t]{2}{*}{ Stability } & Horizontal $\left(\sigma_{y}\right)$ & Vertical $\left(\sigma_{z}\right)$ & & & \\
\hline & $k_{1}$ & $k_{3}$ & $k_{2}$ & $k_{4}$ & $k_{5}$ \\
\hline A & 0.25 & 0.189 & 927 & 0.102 & -1.918 \\
\hline B & 0.202 & 0.162 & 370 & 0.0962 & -0.101 \\
\hline $\mathrm{C}$ & 0.134 & 0.134 & 283 & 0.0722 & 0.102 \\
\hline D & 0.0787 & 0.135 & 707 & 0.0475 & 0.465 \\
\hline E & 0.0566 & 0.137 & 1070 & 0.0335 & 0.624 \\
\hline $\mathrm{F}$ & 0.0370 & 0.134 & 1170 & 0.022 & 0.7 \\
\hline Smith (1968) & & $\sigma=a x^{b}$ & & & \\
\hline \multirow[t]{2}{*}{ Stability } & Horizontal $\left(\sigma_{y}\right)$ & Vertical $\left(\sigma_{z}\right)$ & & & \\
\hline & $a$ & $b$ & $a$ & $b$ & \\
\hline A & 0.4 & 0.91 & 0.41 & 0.91 & \\
\hline B & 0.36 & 0.86 & 0.33 & 0.86 & \\
\hline $\mathrm{C}$ & 0.36 & 0.86 & 0.33 & 0.86 & \\
\hline D & 0.32 & 0.78 & 0.22 & 0.78 & \\
\hline E & 0.32 & 0.78 & 0.22 & 0.78 & \\
\hline $\mathrm{F}$ & 0.31 & 0.71 & 0.06 & 0.71 & \\
\hline
\end{tabular}




\section{The Supplement related to this article is available online at: https://doi.org/10.5194/acp-18-15145-2018- supplement}

Author contributions. DRC, QL and EB-Z implemented the LES modeling for sites. DRC, JML and HML analyzed raw data and provided Gaussian fluxes. DRC, JML, HML, JPF, BB, LMG, XG, JM, DP, LW and MAZ collected in situ data. DRC, LMG, JFP, EB-Z and MAZ assisted in sampling design. LMG, DP, BB and XG provided technical support for data collection and instrument integration. JM provided mechanical assistance in mobile lab design and deployment. MAZ, EB-Z and JPF came up with the overall project design. DRC prepared the manuscript with feedback from all authors.

Competing interests. The authors declare that they have no conflict of interest.

Acknowledgements. We would like to thank all members of the fieldwork team including Stephany Paredes-Mesa, Tanvir Mangat and Kira Olander. We would also like to thank Maider Llaguno Munitxa for her help with the mobile tower modeling. We thank the reviewers for their detailed and helpful comments in the review process. We thank LI-COR Biosciences for lending instrumentation used in this campaign. This work was funded by the NOAA Climate Program Office/Atmospheric Chemistry, Carbon Cycle and Climate, no. NA14OAR4310134.

Edited by: Steven Brown

Reviewed by: Kenneth Davis and one anonymous referee

\section{References}

Agee, E. and Gluhovsky, A.: LES Model Sensitivities to Domains, Grids, and Large-Eddy Timescales, J. Atmos. Sci., 56, 599-605, https://doi.org/10.1175/15200469(1999)056<0599:LMSTDG>2.0.CO;2, 1999a.

Agee, E. and Gluhovsky, A.: Further Aspects of Large Eddy Simulation Model Statistics and Inconsistencies with Field Data, J. Atmos. Sci., 56, 2948-2950, https://doi.org/10.1175/15200469(1999)056<2948:FAOLES>2.0.CO;2, 1999 b.

Albertson, J. D., Harvey, T., Foderaro, G., Zhu, P., Zhou, X., Ferrari, S., Amin, M. S., Modrak, M., Brantley, H., and Thoma, E. D.: A Mobile Sensing Approach for Regional Surveillance of Fugitive Methane Emissions in Oil and Gas Production, Environ. Sci. Technol., 50, 2487-2497, https://doi.org/10.1021/acs.est.5b05059, 2016.

Allen, D. T., Torres, V. M., Thomas, J., Sullivan, D. W., Harrison, M., Hendler, A., Herndon, S. C., Kolb, C. E., Fraser M. P., Hill, A. D., and Lamb, B. K.: Measurements of methane emissions at natural gas production sites in the United States, Proc. Natl. Acad. Sci. USA, 110, 17768-17773, https://doi.org/10.1073/pnas.1304880110, 2013.

Allen, D. T., Pacsi, A. P., Sullivan, D. W., Zavala-Araiza, D., Harrison, M., Keen, K., Fraser, M. P., Hill, A. D., Sawyer,
R. F., and Seinfeld, J. H.: Methane emissions from process equipment at natural gas production sites in the United States: Pneumatic controllers, Environ. Sci. Technol., 49, 633-640, https://doi.org/10.1021/es5040156, 2014.

Baker, L. H., Collings, W. J., Olivie, D. J. L., Cherian, R., Hodnebrog, O., Myhre, G., and Quass, J.: Climate responses to anthropogenic emissions of short-lived climate pollutants, Atmos. Chem. Phys., 15, 8201-8216, https://doi.org/10.5194/acp15-8201-2015, 2015.

Batchelor, G. K.: Diffusion in a field of homogeneous turbulence. I. Eulerian Analysis, Aust. J. Sci. Res., 2, 437-450, https://doi.org/10.1071/CH9490437, 1949.

Black, T. L.: The New NMC Mesoscale Eta Model: Description and Forecast Examples, Weather Forecast., 9, 265-278, https://doi.org/10.1175/1520 0434(1994)009<0265:TNNMEM>2.0.CO;2, 1994.

Bosanquet, C. H. and Pearson, J. L.: The Spread of Smoke and Gases from Chimneys, Trans. Faraday Soc., 32, 1249-1263, 1936.

Bou-Zeid, E., Meneveau, C., and Parlange, M.: A ScaleDependent Lagrangian Dynamic Model for Large Eddy Simulation of Complex Turbulent Flows, Phys. Fluids, 17, 025105, https://doi.org/10.1063/1.1839152, 2005.

Bowerman, N. H. A., Frame, D. J., Huntingford, C., Lowe, J. A., Smith, S. M., and Allen, M. R.: The role of short-lived climate pollutants in meeting temperature goals, Nat. Clim. Change, 3, 1021-1024, https://doi.org/10.1038/nclimate2034, 2013.

Brandt, A. R., Heath, G. A., and Cooley, D.: Methane Leaks from Natural Gas Systems Follow Extreme Distributions, Environ. Sci. Technol., 50, 12512-12520, https://doi.org/10.1021/acs.est.6b04303, 2016.

Brantley, H. L., Thoma, E. D., Squier, W. C., Guven, B. B., and Lyon, D.: Assessment of methane emissions from oil and gas production pads using mobile measurements, Environ. Sci. Technol., 48, 14508-14515, https://doi.org/10.1021/es503070q, 2014.

Briggs, G. A.: Diffusion estimation for small emissions, in environmental research laboratories, Air Resources Atmospheric Turbulence and Diffusion Laboratory 1973 Annual Report, USAEC Report ATDL-106, National Oceanic and Atmospheric Administration, 83-145, 1973.

Caulton, D. and Zondlo, M.: Marcellus Shale Unconventional Natural Gas Well Pad Emissions, available at: https://dataspace. princeton.edu/jspui/handle/88435/dsp01wh246v90d, last access: 10 October 2018.

Caulton, D. R., Shepson, P. B., Santoro, R. L., Sparks, J. P., Howarth, R. W., Ingraffea, A. R., Cambaliza, M. O., Sweeney, C., Karion, A., Davis, K. J., and Stirm, B. H.: Toward a better understanding and quantification of methane emissions from shale gas development, Proc. Natl. Acad. Sci. USA, 111, 6237-6242, https://doi.org/10.1073/pnas.1316546111, 2014.

CCPS (Center for Chemical Profess Safety): Averaging Times, Concentration Fluctuations, and Modeling Uncertainties, in: Guidelines for Use of Vapor Cloud Dispersion Models, 2nd Edn., John Wiley \& Sons, Inc., New York, USA, 1996.

Chester, S., Meneveau, C., and Parlange, M. B.: Modeling turbulent flow over fractal trees with renormalized numerical simulation, J. Comput. Phys., 225, 427-448, https://doi.org/10.1016/j.jcp.2006.12.009, 2007. 
Deardorff, J. W. and Willis, G. E.: Concentration Fluctuations Within a Laboratory Convectively Mixed Layer, Am. Meteorol. Soc., Boston, MA, USA, 357-383, 1988.

de Roode, S. R., Duynkerke, P. G., and Jonker, H. J. J.: Large-Eddy Simulation: How Large is Large Enough?, J. Atmos. Sci., 61, 403-421, https://doi.org/10.1175/15200469(2004)061<0403:LSHLIL>2.0.CO;2, 2004.

Foster-Wittig, T. A., Thoma, E. D., and Albertson, J. D.: Estimation of point source fugitive emission rates from a single sensor time series: A conditionally-sampled Gaussian plume reconstruction, Atmos. Environ., 115, 101-109, https://doi.org/10.1016/j.atmosenv.2015.05.042, 2015.

Frankenberg, C., Thorpe, A. K., Thompson, D. R., Hulley, G., Kort, E. A., Vance, N., Borchardt, J., Krings, T., Gerilowski, K., Sweeney, C., and Conley, S.: Airborne methane remote measurements reveal heavy-tail flux distribution in Four Corners region, Proc. Natl. Acad. Sci. USA, 113, 9734-9739, https://doi.org/10.1073/pnas.1605617113, 2016.

Fritz, B. K., Shaw, B. W., and Parnell, C. B.: Influence of Meteorological Time Frame and Variation on Horizontal Dispersion Coefficients in Gaussian Dispersion Modeling, Trans. A.S.A.E., 48, 1185-1196, https://doi.org/10.13031/2013.18501, 2005.

Gålfalk, M., Olofsson, G., Crill, P., and Bastviken, D.: Making methane visible, Nat. Clim. Change, 6, 426-430, https://doi.org/10.1038/nclimate2877, 2016.

Gifford Jr., F. A.: An outline of theories of diffusion in the lower layers of the atmosphere, in: Meteorology and Atomic Energy, edited by: Slade, D., U.S. Atomic Energy Commission, TID24190, Springfield, Virginia, 65-116, 1968.

Gifford Jr., F. A.: Turbulent diffusion-typing schemes: a review, Nucl. Safety, 17, 68-86, 1976.

Glendening, J. W.: Lineal Eddy Features under Strong Shear Conditions, J. Atmos. Sci., 53, 3430-3449, https://doi.org/10.1175/15200469(1996)053<3430:LEFUSS>2.0.CO;2, 1996.

Goetz, J. D., Floerchinger, C., Fortner, E. C., Wormhoundt, J., Massoli, P., Knighton, W. B., Herndon, S. C., Kolb, C. E., Knipping, E., Shaw, S. L., and DeCarlo, P. F.: Atmospheric Emission Characterization of Marcellus Shale Natural Gas Development Sites, Environ. Sci. Technol., 49, 7012-7020, https://doi.org/10.1021/acs.est.5b00452, 2015.

Hilst, G. R.: The Dispersion of Stack Gases in Stable Atmospheres, J. Air Pollut. Control Assoc., 7, 205-210, https://doi.org/10.1080/00966665.1957.10467804, 1957.

Horst, T. W., Kleissl, J., Lenschow, D. H., Meneveau, C., Moeng, C.-H., Parlange, M. B., Sullivan, P. P., and Weil, J. C.: HATS: Field Observations to Obtain Spatially Filtered Turbulence Fields from Crosswind Arrays of Sonic Anemometers in the Atmospheric Surface Layer, J. Atmos. Sci., 61, 1566-1581, https://doi.org/10.1175/15200469(2004)061<1566:HFOTOS>2.0.CO;2, 2004.

Kang, M., Kanno, C. M., Reid, M. C., Zhang, X., Mauzerall, D. L., Celia, M. A., Chen, Y., and Onstott, T. C.: Direct measurements of methane emissions from abandoned oil and gas wells in Pennsylvania, Proc. Natl. Acad. Sci. USA, 111, 18173-18177, https://doi.org/10.1073/pnas.1408315111, 2014.

Karion, A., Sweeney, C., Pétron, G., Frost, G., Hardesty, R. M., Kofler, J., Miller, B. R., Newberger, T., Wolter, S., Banta, R., and Brewer, A.: Methane emissions estimate from airborne measure- ments over a western United States natural gas field, Geophys. Res. Lett., 40, 4393-4397, https://doi.org/10.1002/grl.50811, 2013.

Karion, A., Sweeney, C., Kort, E. A., Shepson, P. B., Brewer, A., Cambaliza, M., Conley, S. A., Davis, K., Deng, A., Hardesty, M., and Herndon, S. C.: Aircraft-based estimate of total methane emissions from the Barnett Shale region, Environ. Sci. Technol., 49, 8124-8131, https://doi.org/10.1021/acs.est.5b00217, 2015.

Khanna, S. and Brasseur, J. G.: Analysis of Monin-Obukhov similarity from large-eddy simulation, J. Fluid Mech., 345, 251-286, https://doi.org/10.1017/S0022112097006277, 1997.

Kirschke, S., Bousquet, P., Ciais, P., Saunois, M., Canadell, J. G., Dlugokencky, E. J., Bergamaschi, P., Bergmann, D., Blake, D. R., Bruhwiler, L., Cameron-Smith, P., Castaldi, S., Chevallier, F., Feng, L., Fraser, A., Heimann, M., Hodson, E. L., Houweling, S., Josse, B., Fraser, P. J., Krummel, P. B., Lamarque, J.F., Langenfelds, R. L., Le Quéré, C., Naik, V., O’Doherty, S., Palmer, P. I., Pison, I., Plummer, D., Poulter, B., Prinn, R. G., Rigby, M., Ringeval, B., Santini, M., Schmidt, M., Shindell, D. T., Simpson, I. J., Spahni, R., Steele, L. P., Strode, S. A., Sudo, K., Szopa, S., van der Werf, G. R., Voulgarakis, A., van Weele, M., Weiss, R. F., Williams, J. E., and Zeng, G.: Three decades of global methane sources and sinks, Nat. Geosci., 6, 813-823, https://doi.org/10.1038/ngeo1955, 2013.

Kort, E. A., Frankenberg, C., Costigan, K. R., Lindenmaier, R., Dubey, M. K., and Wunch, D.: Four corners: The largest US methane anomaly viewed from space, Geophys. Res. Lett., 41, 6898-6903, https://doi.org/10.1002/2014GL061503, 2014.

Kuai, L., Worden, J. R., Li, K.-F., Hulley, G. C., Hopkins, F. M., Miller, C. E., Hook, S. J., Duren, R. M., and Aubrey, A. D.: Characterization of anthropogenic methane plumes with the Hyperspectral Thermal Emission Spectrometer (HyTES): a retrieval method and error analysis, Atmos. Meas. Tech., 9, 3165-3173, https://doi.org/10.5194/amt-9-3165-2016, 2016.

Kunkel, G. J. and Marusic, I.: Study of the near-wall-turbulent region of the high-Reynolds-number boundary layer using an atmospheric flow, J. Fluid Mech., 548, 375-402, https://doi.org/10.1017/S0022112005007780, 2006.

Lamb, B. K., Edburg, S. L., Ferrara, T. W., Howard, T., Harrison, M. R., Kolb, C. E., Townsend-Small, A., Dyck, W., Possolo, A., and Whetstone, J. R.: Direct measurements show decreasing methane emissions from natural gas local distribution systems in the United States, Environ. Sci. Technol., 49, 5161-5169, https://doi.org/10.1021/es505116p, 2015.

Lan, X., Talbot, R., Laine, P., and Torres, A.: Characterizing fugitive methane emissions in the Barnett Shale area using a mobile laboratory, Environ. Sci. Technol., 49, 8139-8146, https://doi.org/10.1021/es5063055, 2015.

Lavoie, T. N., Shepson, P. B., Cambaliza, M. O., Stirm, B. H., Karion, A., Sweeney, C., Yacovitch, T. I., Herndon, S. C., Lan, X., and Lyon, D.: Aircraft-based measurements of point source methane emissions in the Barnett Shale basin, Environ. Sci. Technol., 49, 7904-7913, https://doi.org/10.1021/acs.est.5b00410, 2015.

Li, Q., Bou-Zeid, E., and Anderson, W.: The Impact and Treatment of the Gibbs Phenomenon in Immersed Boundary Method Simulations of Momentum and Scalar Transport, J. Comput. Phys., 310, 237-251, https://doi.org/10.1016/j.jcp.2016.01.013, $2016 \mathrm{a}$. 
Li, Q., Bou-Zeid, E., Anderson, W., Grimmond, S., and Hultmark, M.: Quality and Reliability of LES of Convective Scalar Transfer at High Reynolds Numbers, Int. J. Heat Mass Transf., 102, 959970, https://doi.org/10.1016/j.ijheatmasstransfer.2016.06.093, 2016b.

Mason, P. J.: Large-Eddy Simulation of Dispersion in Convective Boundary Layers with Wind Shear, Atmos. Environ., 26A, 15611571, https://doi.org/10.1016/0960-1686(92)90056-Q, 1992.

McDermitt, D., Burba, G., Xu, L., Anderson, T., Komissarov, A., Riensche, B., Schedlbauer, J., Starr, G., Zona, D., Oechel, W., Oberbayer, S., and Hastings, S.: A new low-power, open-path instrument for measuring methane flux by eddy covariance, Appl. Phys. B, 102, 391-405, https://doi.org/10.1007/s00340010-4307-0, 2010.

Metzger, M., McKeon, B. J., and Holmes, H.: The nearneutral atmospheric surface layer: turbulence and nonstationarity, Phil. Trans. R. Soc. A, 365, 859-876, https://doi.org/10.1098/rsta.2006.1946, 2007.

Mittal, R. and Iaccarino, G.: Immersed Boundary Methods, Annu. Rev. Fluid Mech., 37, 239-261, https://doi.org/10.1146/annurev.fluid.37.061903.175743, 2005.

Mortarini, L., Stefanello, M., Degrazia, G., Roberti, D., Castelli, S. T., and Anfossi, D.: Characterization of Wind Meandering in Low-Wind-Speed Conditions, Bound.-Lay. Meteorol., 161, 16582, https://doi.org/10.1007/s10546-016-0165-6, 2016.

Nathan, B. J., Golston, L. M., O’Brien, A. S., Ross, K., Harrison, W. A., Tao, L., Lary, D. J., Johnson, D. R., Covington, A. N., Clark, N. N., and Zondlo, M. A.: Near-field characterization of methane emission variability from a compressor station using a model aircraft, Environ. Sci. Technol., 49, 7896-7903, https://doi.org/10.1021/acs.est.5b00705, 2015.

Nickels, T. B., Marusic, I., Hafez, S., Hutchins, N., and Chong, M. S.: Some predictions of the attached eddy model for a high Reynold number boundary layer, Phil. Trans. R. Soc. A, 365, 807-822, https://doi.org/10.1098/rsta.2006.1950, 2007.

Nieuwstadt, F. T. M. and de Valk, J. P. J. M. M.: A Large Eddy Simulation of Buoyant and Non-Buoyant Plume Dispersion in the Atmospheric Boundary Layer, Atmos. Environ., 21, 25732587, https://doi.org/10.1016/0004-6981(87)90189-2, 1987.

Omara, M., Sullivan, M. R., Li, X., Subramanian, R., Robinson, A. L., and Presto, A. A.: Methane emissions from conventional and unconventional natural gas production sites in the Marcellus Shale Basin, Environ. Sci. Technol., 50, 2099-2107, https://doi.org/10.1021/acs.est.5b05503, 2016.

Peischl, J., Ryerson, T. B., Brioude, J., Aikin, K. C., Andrews, A. E., Atlas, E., Blake, D., Daube, B. C., Gouw, J. A., Dlugokencky, E., and Frost, G. J.: Quantifying sources of methane using light alkanes in the Los Angeles basin, California. J. Geophys. Res.Atmos., 118, 4974-4990, https://doi.org/10.1002/jgrd.50413, 2013.

Peischl, J., Ryerson, T. B., Aikin, K. C., Gouw, J. A., Gilman, J. B., Holloway, J. S., Lerner, B. M., Nadkarni, R., Neuman, J. A., Nowak, J. B., and Trainer, M.: Quantifying atmospheric methane emissions from the Haynesville, Fayetteville, and northeastern Marcellus shale gas production regions, J. Geophys. Res.-Atmos., 120, 2119-2139, https://doi.org/10.1002/2014JD022697, 2015.

Peischl, J., Karion, A., Sweeney, C., Kort, E. A., Smith, M. L., Brandt, A. R., Yeskoo, T., Aikin, K. C., Conley, S. A., Gvakharia,
A., and Trainer, M.: Quantifying atmospheric methane emissions from oil and natural gas production in the Bakken shale region of North Dakota, J. Geophys. Res.-Atmos., 121, 61016111, https://doi.org/10.1002/2015JD024631, 2016.

Perry, A. E. and Li., J. D.: Experimental support for the attached-eddy hypothesis in zero-pressure-gradient turbulent boundary layers, J. Fluid Mech., 218, 405-438, https://doi.org/10.1017/S0022112090001057, 1990.

Pétron, G., Frost, G., Miller, B. R., Hirsch, A. I., Montzka, S. A., Karion, A., Trainer, M., Sweeney, C., Andrews, A. E., Miller, L., and Kofler, J.: Hydrocarbon emissions characterization in the Colorado Front Range: A pilot study, J. Geophys. Res.-Atmos., 117, D04304, https://doi.org/10.1029/2011JD016360, 2012.

Pétron, G., Karion, A., Sweeney, C., Miller, B. R., Montzka, S. A., Frost, G. J., Trainer, M., Tans, P., Andrews, A., Kofler, J., and Helmig, D.: A new look at methane and nonmethane hydrocarbon emissions from oil and natural gas operations in the Colorado Denver-Julesburg Basin, J. Geophys. Res.-Atmos., 119, 6836-6852, https://doi.org/10.1002/2013JD021272, 2014.

Ravikumar, A. P., Wang, J., McGuire, M., Bell, C. S., Zimmerle, D., and Brandt, A. R.: "Good versus Good Enough?" Empirical Tests of Methane Leak Detection Sensitivity of a Commercial Infrared Camera, Environ. Sci. Technol., 52, 2368-2374, https://doi.org/10.1021/acs.est.7b04945, 2018.

Rella C. W., Tsai, T. R., Botkin, C. G., Crosson, E. R., and Steele, D.: Measuring emissions from oil and natural gas well pads using the mobile flux plane technique, Environ. Sci. Technol., 49, 4742-4748, https://doi.org/10.1021/acs.est.5b00099, 2015.

Rolph, G., Stein, A., and Stunder, B.: Real-time Environmental Applications and Display sYstem: READY, Environ. Modell. Softw., 95, 210-228, https://doi.org/10.1016/j.envsoft.2017.06.025, 2017.

Roscioli, J. R., Yacovitch, T. I., Floerchinger, C., Mitchell, A. L., Tkacik, D. S., Subramanian, R., Martinez, D. M., Vaughn, T. L., Williams, L., Zimmerle, D., Robinson, A. L., Herndon, S. C., and Marchese, A. J.: Measurements of methane emissions from natural gas gathering facilities and processing plants: measurement methods, Atmos. Meas. Tech., 8, 20172035, https://doi.org/10.5194/amt-8-2017-2015, 2015.

Salesky, S. T. and Chemecki, M.: Random Errors in Turbulence Measurements in the Atmospheric surface Layer: Implications for Monin-Obukhov Similarity Theory, J. Atmos. Sci., 69, 37003714, https://doi.org/10.1175/JAS-D-12-096.1, 2012.

Seinfeld, J. H. and Pandis, S. N.: Atmospheric Chemistry and Physics. John Wiley \& Sons, Inc. Hoboken, New Jersey, U.S.A., 828-896, 1998.

Shah, S. and Bou-Zeid, E.: Very-Large-Scale Motions in the Atmospheric Boundary Layer Educed by Snapshot Proper Orthogonal Decomposition, Bound.-Lay. Meteorol., 153, 355-387, https://doi.org/10.1007/s10546-014-9950-2, 2014.

Smith, M. E.: Recommended guide for the prediction of the dispersion of airborne effluents, ASME, New York, 1968.

Subramanian, R., Williams, L. L., Vaughn, T. L., Zimmerle, D., Roscioli, J. R., Herndon, S. C., Yacovitch, T. I., Floerchinger, C., Tkacik, D. S., Mitchell, A. L., and Sullivan, M. R.: Methane Emissions from Natural Gas Compressor Stations in the Transmission and Storage Sector: Measurements and Comparisons with the EPA Greenhouse Gas Re- 
porting Program Protocol, Envir. Sci. Tech., 49, 3252-3261, https://doi.org/10.1021/es5060258, 2015.

Sutton, O. G.: A Theory of Eddy Diffusion in the Atmosphere, P. R. Soc. Lond. A-Conta., 135, 143-165, 1932.

Tao, L., Sun, K., Miller, D. J., Pan, D., Golston, L. M., and Zondlo, M. A.: Low-power, open-path mobile sensing platform for high-resolution measurements of greenhouse gases and air pollutants, Appl. Phys. B-Lasers O., 119, 153-164, https://doi.org/10.1007/s00340-015-6069-1, 2015.

Thorpe, A. K., Frankenberg, C., Aubrey, A. D., Roberts, D. A., Nottrott, A. A., Rahn, T. A., Sauer, J. A., Dubey, M. K., Costigan, K. R., Arata, C., and Steffke, A. M.: Mapping methane concentrations from a controlled release experiment using the next generation Airborne Visible/Infrared Imaging Spectrometer (AVIRIS-NG), Remote Sens. Environ., 179, 104-115, https://doi.org/10.1016/j.rse.2016.03.032, 2016.

Townsend, A. A.: Equilibrium layers and wall turbulence, J. Fluid. Mech., 11, 97-120, https://doi.org/10.1017/S0022112061000883, 1961.

Townsend-Small, A., Marrero, J. E., Lyon, D. R., Simpson, I. J., Meinardi, S., and Blake, D. R.: Integrating source apportionment tracers into a bottom-up inventory of methane emissions in the Barnett Shale hydraulic fracturing region, Environ. Sci. Technol., 49, 8175-8182, https://doi.org/10.1021/acs.est.5b00057, 2015.

Tseng, Y. H., Meneveau, C., and Parlange, M. B.: Modeling Flow Around Bluff Bodies and Predicting Urban Dispersion Using Large Eddy Simulation, Environ. Sci. Technol., 40, 2653-2662, https://doi.org/10.1021/es051708m, 2006.

U.S. EPA: Other Test Methods (OTM) 33 and 33A Geospatial Measurement of Air Pollution-Remote Emissions Quantification Direct Assessment (GMAP-REQ-DA), available at: https://www3. epa.gov/ttnemc01/prelim/otm33a.pdf (last access: 1 May 2018), 2014.

Veigele, W. J. and Head, J. H.: Derivation of the Gaussian Plume Model, J. Air Pollut. Control Assoc., 28, 1139-1140, https://doi.org/10.1080/00022470.1978.10470720, 1978.

Venkatram, A. and Wyngaard, J. C (Eds.).: Lectures on Air Pollution Modeling, American Meteorological Society, Boston, Massachusetts, U.S.A., 1988.
Vickers, D., Mahrt, L., and Belusic, D.: Particle simulations of dispersion using observed meandering and turbulence, Acta Geophys., 56, 234-256, https://doi.org/10.2478/s11600-007-0041-3, 2008.

Weil, J. C.: A Diagnosis of the Asymmetry in Top-Down and Bottom-Up Diffusion Using a Lagrangian Stochastic Model, J. Atmos. Sci., 47, 501-515, https://doi.org/10.1175/15200469(1990)047<0501:ADOTAI>2.0.CO;2, 1990.

Weil, J. C., Sullivan, P. P., and Moeng, C.-H.: The Use of LargeEddy Simulations in Lagrangian Particle Dispersion Models, J. Atmos. Sci., 61, 2877-2887, https://doi.org/10.1175/JAS3302.1, 2004.

Woodcock, J. D. and Marusic, I.: The statistical behaviour of attached eddies, Phys. Fluids, 27, 015104, https://doi.org/10.1063/1.4905301, 2015.

Wyngaard, J. C. and Weil, J. C.: Transport asymmetry in skewed turbulence, Phys. Fluids, 3, 155-162, https://doi.org/10.1063/1.857874, 1991.

Yacovitch, T. I., Herndon, S. C., Pétron, G., Kofler, J., Lyon, D., Zahniser, M. S., and Kolb, C. E.: Mobile Laboratory Observations of Methane Emissions in the Barnett Shale Region, Environ. Sci. Technol., 49, 7889-7895, https://doi.org/10.1021/es506352j, 2015.

Zannetti, P.: Air Pollution Modeling: Theories, Computational Methods, and Available Software, Van Nostrand Reinhold, New York, U.S.A., 141-183, 1990.

Zickfeld, K., Solomon, S., and Gilford, D. M.: Centuries of thermal sea-level rise due to anthropogenic emissions of short- lived greenhouse gases, Proc. Natl. Acad. Sci. USA, 114, 657-662, https://doi.org/10.1073/pnas.1612066114, 2017.

Zimmerle, D. J., Williams, L. L., Vaughn, T. L., Quinn, C., Subramanian, R., Duggan, G. P., Willson, B., Opsomer, J. D., Marchese, A. J., Martinez, D. M., and Robinson, A. L.: Methane emissions from the natural gas transmission and storage system in the United States, Environ. Sci. Technol., 49, 9374-9383, https://doi.org/10.1021/acs.est.5b01669, 2015. 